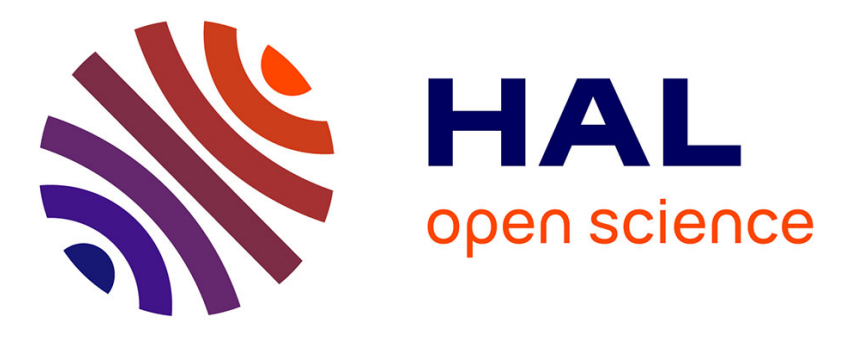

\title{
Experimental and modeling study of the pyrolysis and combustion of 2-methyl-tetrahydrofuran
}

Ruben de Bruycker, Luc-Sy Tran, Hans-Heinrich Carstensen, Pierre-Alexandre Glaude, Fabiola Monge, Maria Alzueta, Frédérique Battin-Leclerc, Kevin M van Geem

\section{To cite this version:}

Ruben de Bruycker, Luc-Sy Tran, Hans-Heinrich Carstensen, Pierre-Alexandre Glaude, Fabiola Monge, et al.. Experimental and modeling study of the pyrolysis and combustion of 2-methyl-tetrahydrofuran. Combustion and Flame, 2017, 176, pp.409-428. 10.1016/j.combustflame.2016.11.017 . hal-02928433

\section{HAL Id: hal-02928433 \\ https://hal.science/hal-02928433}

Submitted on 2 Sep 2020

HAL is a multi-disciplinary open access archive for the deposit and dissemination of scientific research documents, whether they are published or not. The documents may come from teaching and research institutions in France or abroad, or from public or private research centers.
L'archive ouverte pluridisciplinaire HAL, est destinée au dépôt et à la diffusion de documents scientifiques de niveau recherche, publiés ou non, émanant des établissements d'enseignement et de recherche français ou étrangers, des laboratoires publics ou privés. 


\section{Experimental and modeling study of the pyrolysis and combustion of 2-methyl-tetrahydrofuran}

Ruben De Bruycker ${ }^{1}$, Luc-Sy Tran ${ }^{1,2, \#}$, Hans-Heinrich Carstensen ${ }^{1}$,Pierre-Alexandre Glaude ${ }^{2}$, Fabiola Monge ${ }^{3}$, Maria U. Alzueta ${ }^{3}$, Frédérique Battin-Leclerc ${ }^{2}$, Kevin M. Van Geem ${ }^{1, *}$

${ }^{1}$ Laboratory for Chemical Technology (LCT), Ghent University, Technologiepark 914, 9052 Gent, Belgium

${ }^{2}$ Laboratoire Réactions et Génie des Procédés (LRGP), CNRS, Université de Lorraine, ENSIC, 1 rue Grandville, BP 20451, 54001 Nancy Cedex, France

${ }^{3}$ Aragón Institute of Engineering Research, University of Zaragoza, Mariano Esquillor, 50018 Zaragoza, Spain

\# Now at Department of Chemistry, Bielefeld University, Universitätsstraße 25, D-33615 Bielefeld, Germany

* Corresponding author, e-mail: Kevin.VanGeem@UGent.be phone: +32 (0)9 2645597 


\section{Abstract}

Saturated cyclic ethers are being proposed as next-generation bio-derived fuels. However, their pyrolysis and combustion chemistry has not been well established. In this work, the pyrolysis and combustion chemistry of 2-methyl-tetrahydrofuran (MTHF) was investigated through experiments and detailed kinetic modeling. Pyrolysis experiments were performed in a dedicated plug flow reactor at $170 \mathrm{kPa}$, temperatures between 900 and $1100 \mathrm{~K}$ and a $\mathrm{N}_{2}$ (diluent) to MTHF molar ratio of 10 . The combustion chemistry of MTHF was investigated by measuring mole fraction profiles of stable species in premixed flat flames at $6.7 \mathrm{kPa}$ and equivalence ratios 0.7 , 1.0 and 1.3 and by determining laminar burning velocities of MTHF/air flat flames with unburned gas temperatures of 298, 358 and $398 \mathrm{~K}$ and equivalence ratios between 0.6 and 1.6. Furthermore, a kinetic model for pyrolysis and combustion of MTHF was developed, which contains a detailed description of the reactions of MTHF and its derived radicals with the aid of new high-level theoretical calculations. Model calculated mole fraction profiles and laminar burning velocities are in relatively good agreement with the obtained experimental data. At the applied pyrolysis conditions, unimolecular decomposition of MTHF by scission of the methyl group and concerted ring opening to 4-penten-1-ol dominates over scission of the ring bonds; the latter reactions were significant in tetrahydrofuran pyrolysis. MTHF is mainly consumed by hydrogen abstraction reactions. Subsequent decomposition of the resulting radicals by $\beta$-scission results in the observed product spectrum including small alkenes, formaldehyde, acetaldehyde and ketene. In the studied flames, unimolecular ring opening of MTHF is insignificant and consumption of MTHF through radical chemistry dominates. Recombination of 2-oxo-ethyl and 2-oxo-propyl, primary radicals in MTHF decomposition, with hydrogen atoms and carboncentered radicals results in a wide range of oxygenated molecules. 
Keywords: Bio-fuel, 2-methyl-tetrahydrofuran, pyrolysis, laminar premixed flame, detailed kinetic model. 


\section{Introduction}

There is an increased demand for a sustainable production of chemicals and fuels. Currently, a lot of effort is dedicated to the conversion of lignocellulosic biomass through catalytic, fermentative and pyrolytic processes. These conversion routes result in a wide variety of molecules that may be processed further into other high-value chemicals, so-called platform molecules, or that can be used directly, for example as bio-fuel.

Recently, several production routes to saturated cyclic ethers, such as 2-methyl-tetrahydrofuran (MTHF) and 2,5-dimethyl-tetrahydrofuran (DMTHF), have been proposed [1-3]. This class of molecules has lower heating values that range between $28.5 \mathrm{MJ} \mathrm{l}^{-1}$ and $29.5 \mathrm{MJ} \mathrm{l}^{-1}$, which are close to those of furans $\left(\sim 27.7-30.0 \mathrm{MJ} \mathrm{1}^{-1}\right)$ and of gasoline $\left(\sim 31.6 \mathrm{MJ} \mathrm{1}^{-1}\right)$, but clearly higher than that of ethanol ( 21.3 $\left.\mathrm{MJ} \mathrm{l}^{-1}\right)$. MTHF has good antiknock characteristics (RON=86, MON=73), and satisfactory performance when mixed with gasoline in a conventional internal combustion engine [4-7].

The potential of cyclic ethers to serve as next-generation bio-derived fuels has triggered several fundamental studies that aim at understanding their combustion chemistry. Tetrahydrofuran (THF), the simplest five-membered cyclic ether, has received most attention. Verdicchio et al. investigated the unimolecular decomposition of THF using quantum chemical methods [8]. The calculations show that biradical and carbene intermediates play an important role in the initial ring-opening steps, but that a concerted molecular channel is also active. Model simulations with a kinetic model based on the mentioned ab initio study are in good agreement with shock tube experiments [9]. Tran et al. expanded the model to describe the combustion chemistry of THF. The model was validated with data obtained from premixed flames and shock tube measurements [10]. Kasper et al. investigated the structure of laminar premixed low-pressure 
THF flames using photoionization (PI) and electron-ionization (EI) molecular-beam mass spectrometry (MBMS) [11]. THF oxidation and ignition has been studied in jet-stirred reactors and a rapid compression machine $[12,13]$. The available experimental data and developed kinetic models of the aforementioned studies indicate that THF decomposition is dominated by radical chemistry as soon a radical pool is established.

The pyrolysis and combustion chemistry of alkylated cyclic ethers is less well established. A theoretical study by Simmie provides thermochemistry for THF, MTHF, DMTHF and the derived radicals, and kinetic data for a selection of hydrogen abstraction and radical decomposition reactions [14]. Other quantum chemical studies have focused on hydrogen abstraction from MTHF and DMTHF by hydroperoxy radicals [15] and intramolecular hydrogen abstraction of the various peroxy radicals formed from 3-methyl-tetrahydrofuran [16]. Fuel rich $(\varphi=1.7)$, low pressure, premixed laminar MTHF flames were investigated by Moshammer et al. [17]. Reaction products were identified and quantified using molecular beam mass spectrometry with electron ionization and synchrotron-based tunable VUV photoionization. A kinetic model was developed using the theoretical study by Simmie [14] and analogy with other molecules.

This work aims to improve the understanding of the pyrolysis and combustion chemistry of MTHF, see Fig. 1. Firstly, the experimental database for MTHF reactions is expanded in several ways. The pyrolysis chemistry is investigated in a tubular plug flow reactor. Furthermore, temperature and mole fraction profiles are measured in three low-pressure premixed flames while laminar burning velocities are obtained at atmospheric pressure using the heat flux method. Secondly, a new detailed kinetic model for MTHF pyrolysis and combustion has been developed. Kinetic data related to the decomposition of MTHF has been calculated using the CBS-QB3 level of theory. Thirdly, predictions of the new kinetic model are compared to the 
obtained experimental data. Reaction path and sensitivity analyses are performed to better understand the MTHF chemistry. The proposed kinetic model is meant to serve as a building block for biomass pyrolysis and gasification processes as the cyclic ether structure is present in some biomass model compounds.

\section{Experimental and computational methods}

The pyrolysis chemistry of MTHF was studied in a plug flow reactor. The combustion chemistry was studied using premixed, laminar flames. A detailed description of the experimental setups used in this study has been given elsewhere [18-23]. Only the main features of the experimental and analytical methods used are summarized below. Operating conditions are listed in Table 1.

\subsection{Tubular flow reactor for pyrolysis}

MTHF (Sigma Aldrich, state purity $+99 \%$ ) is fed to an evaporator kept at $573 \mathrm{~K}$ using a Coriolis flow meter controlled pump. Nitrogen (Air Liquide, purity $+99.999 \%$ ) is used as diluent and its flow rate is controlled using a Coriolis mass flow controller. It is heated to the same temperature as MTHF and both gasses are mixed $\left(\mathrm{V}_{\text {pre-mixing zone }}=510^{-4} \mathrm{~m}^{3}\right)$ before entering the reactor.

The tubular reactor has an internal diameter of $6 \mathrm{~mm}$ and is $1.475 \mathrm{~m}$ long. The reactor is placed in an electrically heated furnace. In total, eight thermocouples are positioned along the reactor length, measuring the gas temperature. The reactor consists of 4 separate sections and the temperature in each section is controlled by a thermocouple. Furthermore, two manometers, positioned at the inlet and outlet of the reactor, measure the pressure. The pressure was kept fixed at $0.17 \mathrm{MPa}$ using a valve positioned downstream of the reactor. The pressure drop across the reactor was found to be negligible $(<0.001 \mathrm{MPa})$. 
Products and unconverted feed are identified and quantified online, downstream of the reactor, using several dedicated gas chromatographs. The reactor effluent is first sent to a heated sampling system kept at $573 \mathrm{~K}$ to avoid condensation. A part of the mixture is injected on a refinery gas analyzer (RGA) after removal of the condensable fraction. This chromatograph is able to calculate the flow rate of all permanent gases using two thermal conductivity detectors (TCD) and $\mathrm{C}_{4}$ - hydrocarbons using a flame ionization detector (FID) based on the fixed flow rate of $\mathrm{N}_{2}$, i.e. primary internal standard. A different fraction of the effluent is injected on a two dimensional gas chromatograph $(\mathrm{GCxGC})$ and a light oxygenates analyzer (LOA) through heated transfer lines, without prior condensation. The flow rate of water, formaldehyde and methanol are calculated using the LOA, equipped with a TCD, with propene, identified and quantified on the RGA, as secondary internal standard. The GCxGC allows identification, using a time-of-flight mass spectrometer (TOF-MS), and quantification, using a FID, of all hydrocarbons and oxygenated molecules that have two or more carbon atoms. Methane, identified and quantified on the RGA, acts as secondary internal standard. This methodology allows online analysis of the complete product spectrum and avoids separate gas-phase and condensate analysis. A more detailed description of data quantification can be found elsewhere[24].

The procedure described above allowed closing $\mathrm{C}, \mathrm{H}$ and $\mathrm{O}$ molar balances within $5 \%$. Several repeat experiments were performed and the average uncertainty on product mole fraction is $5 \%$, in line with previous experiments.

\subsection{Low-pressure premixed flat flame structure}

The flow rates of oxygen (Messer, purity $+99.995 \%$ ) and argon (Messer, purity $+99.999 \%$ ), the diluent, are controlled by two mass flow controllers (Bronkhorst). The flow rate of liquid MTHF 
(Sigma Aldrich, purity $+99 \%$ ) is regulated using a mass flow controller connected to a evaporator/mixer (Bronkhorst). There, MTHF is evaporated and mixed with argon. Subsequently, the gaseous stream is mixed with oxygen and fed to a McKenna burner $(60 \mathrm{~mm}$ diameter) housed in a vacuum chamber. The temperature of the burner is kept at $333 \mathrm{~K}$ using water cooling.

Three premixed flames, i.e. $\varphi=0.7,1.0$ and 1.3 ,were stabilized on the burner. The volumetric flow rate of the unburned gas was constant for all equivalence ratios, see Table 1 . The pressure was fixed at $6.7 \mathrm{kPa}$ (50 Torr). The flame was connected with three gas chromatographs (GC) through a quartz probe, with a $0.18 \mathrm{~mm}$ diameter orifice at the tip and an angle to vertical of $22^{\circ}$, and heated transfer lines kept at $423 \mathrm{~K}$. The first GC was equipped with a carbosphere column and was used to quantify oxygen and hydrogen using a TCD detector. The second GC was equipped with a HP-PLOT $\mathrm{Q}$ column and was used to quantify $\mathrm{CO}, \mathrm{CO}_{2}$, oxygenates, hydrocarbons using a FID detector preceded by a methanizer and water using a TCD detector. This GC was also equipped with a HP-Molsieve column and was used to quantify $\mathrm{CO}$ and $\mathrm{CH}_{4}$ using a FID detector and argon using a TCD detector. The third GC was equipped with a HPPLOT Q column and a mass spectrometer and was used for species identification. Species mole fraction profiles as function of height above the burner were obtained by moving the burner in vertical direction and keeping the position of the sampling probe fixed.

Flame temperature profiles were measured with a $\operatorname{PtRh}(6 \%)-\operatorname{PtRh}(30 \%)$ type B thermocouple (diameter $0.10 \mathrm{~mm}$ ). The thermocouple junction was located at the center of the burner. The thermocouple was coated with a ceramic layer of $\mathrm{BeO}-\mathrm{Y}_{2} \mathrm{O}_{3}$ to reduce catalytic effects.

The electrical compensation method was used to correct for radiative heat losses. In a flame, the temperature is high causing the thermocouple wire to emit thermal radiation to the environment, 
causing heat losses. These losses of heat by radiation cannot be avoided and become very important at high temperatures $(\mathrm{T}>1200 \mathrm{~K}$ ). Consequently, the thermocouple temperature becomes lower than the actual temperature of the flame. To compensate for these losses, a correction was performed. This correction is performed using the method of thermal compensation by Joule effect proposed by Bonne et al. [25]. The idea of this correction is to use the Joule effect, using an electrical current through the thermocouple, to exactly compensate for the radiative losses.

The estimated uncertainty of the measured temperature values is approximately $5 \%$.

A sighting telescope (cathetometer) was used to evaluate the position of the probe and the thermocouple with respect to the burner, accuracy $+/-0.05 \mathrm{~mm}$.

The described procedure allowed closing the $\mathrm{C}$ molar balance within $5 \%$ and the $\mathrm{O}$ and $\mathrm{H}$ molar balances within $10 \%$. Uncertainties on the mole fraction measurements of the quantified species were $\sim 5 \%$ for the major compounds and $\sim 15 \%$ for minor products $(<100 \mathrm{ppm})$, which were estimated mainly based on the error of mass flow controllers, of GC calibration methods, and the effect of signal-to-noise ratios. The FID and TCD detection limits were about 1 ppm and 50 ppm, respectively.

\subsection{Laminar burning velocities measurements in atmospheric flat flame}

Laminar burning velocities were measured using the heat flux method applied to a flat flame adiabatic burner [26]. The apparatus consists of a plenum chamber attached to a brass burner plate. The temperature of the plenum chamber was set to the desired unburned gas temperature using a thermostatic oil jacket. The brass burner plate is $2 \mathrm{~mm}$ thick and has a diameter of 30 $\mathrm{mm}$. The plate is perforated with holes of diameter $0.5 \mathrm{~mm}$, with the pitch between them being 
$0.7 \mathrm{~mm}$. Eight thermocouples are embedded into the plate surface at different distances and angles from the center to the periphery of the burner to measure the radial temperature profile. Heating around the burner plate was provided by thermostatic oil, at $50 \mathrm{~K}$ higher than the unburned gas temperature. The heat flux from the heated burner to the unburned gas can compensate for heat losses from the flame toward the heated burner, which results in adiabatic conditions. The radial burner temperature profile becomes flat and the gas speed equals the adiabatic burning velocity.

In the present study, the measurements of laminar burning velocity were performed at atmospheric pressure $(101.3 \mathrm{kPa})$, for unburned flame temperatures ranging from 298 to $398 \mathrm{~K}$, and equivalence ratios from 0.60 to 1.55 .

The global estimated error of the laminar burning velocity is $\sim 5 \%$. The error estimation is described in detail in [21]. Briefly, the error was induced by the error in the mass flow measurements $(\sim 1.5 \%)$, in the reading of the temperature with thermocouples ( averaged error $\sim 0.6 \%$ in the present data), and by flame distortions (averaged error $\sim 0.6 \%$ in the present data). Moreover, the temperature of the unburned gas mixture before and after it flowed through the plenum chamber was measured with a thermocouple with an estimated error of $2 \mathrm{~K}$ resulting in an error of $\sim 0.9 \%$ in the present laminar flame velocities. In addition, the error in the equivalence ratio is about $1 \%$, resulting mainly from the error in the mass flow measurements for oxygen and liquid fuel, which induces an error $\sim 1.8 \%$ in the present laminar flame velocities.

\subsection{Computational methods}

The rate coefficients for the concerted MTHF decomposition, several hydrogen abstraction reactions and unimolecular decomposition channels of the resulting radicals were calculated in 
two steps. First, electronic structure calculations at the CBS-QB3 level of theory [27] were performed using the Gaussian 09 revision D suite of programs [28]. Using methods from statistical mechanics, the output of the ab initio calculations was used to determine the thermodynamic properties of reactants, products and transition states. Heats of formation are obtained from the electronic energies by converting those with the atomization method. B3LYP/6-311G(d,p) level rotational constants and scaled (factor 0.99) harmonic frequencies, except those that represent internal rotations, were used to calculate the thermal contributions to the enthalpies as well as entropies and heat capacities. Hindrance potentials of internal rotors, which are not well described as harmonic oscillators, were determined via relaxed scans by increasing the corresponding dihedral angle in 10 degrees steps until complete rotation was achieved. These potentials were regressed to Fourier series prior to their use. The reduced moments of inertia were calculated at the $I^{(2,3)}$ level as defined by East and Radom [29]. With this information, the Schrödinger equation for one-dimensional axis-fixed rotation could be solved and the resulting energy eigenvalues were employed to calculate the contributions of these modes to the thermodynamic functions. Finally, the thermodynamic data was stored in form of NASA polynomials.

In the second step, transition state theory expressed in terms of Gibbs free energies was used to calculate the rate coefficients:

$$
\mathrm{k}_{\mathrm{TST}}(\mathrm{T})=\chi(\mathrm{T}) \cdot \frac{\mathrm{k}_{\mathrm{B}} \mathrm{T}}{\mathrm{h}} \cdot\left(\frac{\mathrm{RT}}{\mathrm{p}}\right)^{\Delta \mathrm{n}-1} \cdot \mathrm{e}^{-\frac{\Delta \mathrm{G}^{\ddagger}}{\mathrm{RT}}}
$$

Here $\Delta G^{\ddagger}$ is the Gibbs free energy difference between transition state without the transitional mode and reactant(s), $\Delta n$ is the molecularity of the reaction (2 for bimolecular, 1 for unimolecular reactions), and $\chi(T)$ is a correction factor that accounts for quantum mechanical 
tunneling. All other symbols have their usual meaning. The asymmetric Eckart potential was used in this work to calculate $\chi(T)$. The Gibbs free energies were obtained from the NASA polynomials calculated in the first step. Rate coefficients were calculated for temperatures ranging between $300 \mathrm{~K}$ and $2500 \mathrm{~K}$ in $50 \mathrm{~K}$ steps. The individual rate coefficients were finally regressed to modified Arrhenius expressions.

A comparison between the reaction rate coefficients calculated in this work with those provided by Simmie [14] and Moshammer et al. [17] can be found in Supplementary Material.

\section{Simulations}

Simulations were performed using the CHEMKIN package [30].

The plug flow reactor module was used to simulate the pyrolysis experiments. The plug flow assumption has been validated earlier for the used reactor setup [31].

The simulations for the low-pressure premixed flames were conducted using the premixed laminar burning-stabilized flame module. Composition and flow rate of the inlet stream, pressure and temperature profile were provided as input. In this work, the input temperature profile is the average of the measured temperature profile with and without the sampling probe, in line with earlier studies [10]. The use of the average temperature profile tries to account for the distortion of the flame structure induced by sampling probe and thermocouple: (i) The measured temperature profile without the sampling probe overestimates the temperature as the sampling probe acts as a heat sink; (ii) The measured temperature profile with the sampling probe underestimates the temperature as the probe mainly affects the temperature of the gas near the probe, and not necessarily the temperature of the gas near the burner. The measured temperature profile with the sampling probe, the measured temperature profile without the sampling probe 
and the temperature profile used for simulation at $\varphi=1.0$ are presented in Fig. 2 as example. In Fig. 2, the average temperature difference between the temperature with and without sampling probe is approximately $130 \mathrm{~K}$. The temperature profiles for the $\varphi=0.7$ and 1.3 flames can be found in Supplementary Material.

Simulations of adiabatic laminar burning velocities were carried out using the premixed laminar flame-speed module with GRAD and CURV parameters of 0.05. Thermal diffusion effects were included in the simulations.

\section{Kinetic Model Development}

A detailed kinetic model has been developed to describe the pyrolysis and combustion of MTHF. The model consist of three main parts: (1) a primary mechanism, describing the combustion and pyrolysis of MTHF and derived radicals, (2) a base mechanism, describing the combustion and pyrolysis of small hydrocarbons and oxygenates, (3) a secondary mechanism, describing the combustion and pyrolysis of products originating from MTHF decomposition and not described by the base mechanism.

Compared to the model proposed by Moshammer et al.[17], the description of primary MTHF reactions, especially decomposition of MTHF-derived radicals, is more detailed in the developed kinetic model. The bulk of these reactions were calculated at the CBS-QB3 level of theory, instead of rate rules and analogy. Furthermore, the developed kinetic model is able to describe the formation of experimentally-detected oxygenated species, such as large aldehydes, large ketones and 4-penten-1-ol. These molecules are not present in the kinetic model proposed by Moshammer et al. [17]. 
The complete kinetic model can be found in Supplementary Material. Each species is accompanied by its IUPAC International Chemical Identifier (InChI) which allows to unambiguously identify the molecular structure. A selection of key reactions of the primary mechanism and their corresponding rate coefficients are presented in Table 2. The three parts of the model are described in the following sections.

\subsection{Primary mechanism}

The primary mechanism consists of reactions describing the consumption of MTHF by unimolecular reactions and bimolecular reactions, e.g. hydrogen abstraction, and decomposition of MTHF-derived radicals, e.g. $\beta$-scission reactions.

\section{Unimolecular fuel decomposition}

Scission of the methyl - ring bond and scission of the $\mathrm{C}-\mathrm{H}$ bonds produce radical species. Reaction rate coefficients were estimated in the reverse direction, i.e. recombination (reactions 1$6)$.

Unimolecular ring opening by scission of one of the ring bonds produces diradical or carbenic species. These reactions were found to be important in THF pyrolysis [8]. Diradical and carbenic species are unstable and react to molecular products by intramolecular hydrogen abstraction or $\beta$ scission. In the work by Tran et al. [10] the pseudo steady state approximation was applied to diradical and carbenic species. This allowed to replace diradical and carbenic species in the unimolecular ring opening reactions by their molecular products following intramolecular hydrogen abstraction or $\beta$-scission. Therefore, diradical and carbenic species are no longer explicitly present in the kinetic model but are still implicitly present in the unimolecular ring opening reactions. A similar strategy was used in this work for unimolecular ring opening of 
MTHF, see reactions 7-20 in Table 2. Corresponding reaction rate coefficients were taken from their THF-analogues [10].

For example, C-O scission in THF may form 3-hydroxypropyl carbene [8], see Fig. 3. Isomerization of the carbene to but-3-en-1-ol is favored over decomposition to ethenol and ethene [8]. The analogous reactions for MTHF are added to Fig. 3. C-O scission in MTHF can form methyl,3-hydroxypropyl carbene which can react to pent-3-en-1-ol. The equivalent singlestep reaction is reaction number 13 in Table 2. C-O scission in MTHF can also form 3-methyl-3hydroxypropyl carbene which can react to pent-4-en-2-ol. The equivalent single-step reaction is reaction number 14 in Table 2. Rate coefficients for the latter two reactions are taken from their THF analogue [10].

Note that the use of the reaction rate coefficients of THF for MTHF introduces some error to the kinetic model. In the case of the analogous reactions in Fig. 3, C-O scission in THF forms 3hydroxypropyl carbene where a primary carbon atom has valence two while C-O scission in MTHF can form methyl-3-hydroxypropyl carbene where a secondary carbon atom has valence two. The effect of this error on the performance of the kinetic model is expected to be minor as scission of one of the ring bonds is typically of lower importance compared to C-C scission of the alkyl side group, as in methyl-cyclohexane [32].

Ethers can react through a 4-membered transition state where a hydrogen atom of a carbon atom in $\beta$-position bridges to the oxygen atom forming an alkene and an alcohol [33]. Three such reactions are considered for MTHF. Hydrogen atoms from ring carbon atoms in the $\beta$-position can bridge to the oxygen atom forming pent-3-en-1-ol and pent-4-en-2-ol respectively, reactions 20 and 21 in Table 2. Rate coefficients were taken from the analogous THF reaction [8]. Furthermore, a hydrogen atom of the methyl groups can bridge to the ring oxygen forming 4- 
penten-1-ol, reaction 19 in Table 2. The detection of the latter molecule in pyrolysis conditions, see section 4.1, motivated the calculation of the corresponding reaction rate coefficients at the CBS-QB3 level of theory. The rate coefficient of reaction 19 is approximately a factor 1000 faster than reactions 20 and 21 at $1000 \mathrm{~K}$, as can be observed from Table 2 . Therefore, reactions 20 and 21 will be unimportant in the investigated experimental operating conditions.

\section{Hydrogen abstraction from $\mathrm{MTHF}$}

Reaction rate coefficients for hydrogen abstraction reactions from MTHF by hydrogen atoms and methyl radicals (reactions 22-31) were derived from quantum calculations in the present study. Reaction rate coefficients for hydrogen abstraction by oxygen atoms, hydroxyl radicals (reactions 32-41) were deduced from Evans-Polanyi correlations proposed by Dean and Bozelli [34], analogous to recently developed tetrahydrofuran and tetrahydropyran kinetic models [10, 35]. Kinetics for hydrogen abstraction from MTHF by hydroperoxy radicals (reactions 42-46) were taken from the theoretical calculations by Chakravarty et al. [15]. Hydrogen abstraction reactions by carbon centered radicals, such as ethyl and allyl, were estimated from hydrogen abstraction by methyl but taking into consideration the effect of resonance stabilization [36, 37].

\section{MTHF radical decomposition}

Decomposition reactions of all MTHF radicals and ring-opened MTHF radicals have been calculated at the CBS-QB3 level of theory, see Table 2 (reactions 47-55, 57-66, 69-81, 85-89, 91-97). MTHF radicals can undergo ring opening reactions by $\mathrm{C}-\mathrm{C} \beta$-scission and $\mathrm{C}-\mathrm{O} \beta$ scission. Previous studies regarding THF and MTHF indicated that ring opening by $\mathrm{C}-\mathrm{O} \beta-$ scission is favored over C-C $\beta$-scission $[10,14]$. The same trend is observed in this work. Unsaturated cyclic ethers can be formed by C-H $\beta$-scission of MTHF radicals (reactions 56, 67, 
$68,82,83,90$ ) and $\mathrm{C}-\mathrm{C} \beta$-scission of the methyl side group (reaction 74) in the case of tetrahydro-2-methyl-3-furanyl.

The ring-opened MTHF radicals can fragment by $\beta$-scission or react by intramolecular hydrogen abstraction and intramolecular radical addition. Ring opening of tetrahydro-2-methyl-4-furanyl and subsequent decomposition is presented as example in Fig. 4. The dominant consumption path of 1-allyloxy-ethyl radical, formed by C-C $\beta$-scission of tetrahydro-2-methyl-4-furanyl, is $\mathrm{C}-\mathrm{O} \beta$-scission to acetaldehyde plus allyl. A minor path is exo-intramolecular radical addition to 3-methylene-2-methyl-oxetane. The latter radical is also formed by exo-intramolecular radical addition of the 3-buten-2-yloxy-methyl radical, formed by $\mathrm{C}-\mathrm{C} \beta$-scission of tetrahydro-2methyl-3-furanyl. Hence, tetrahydro-2-methyl-3-furanyl and tetrahydro-2-methyl-4-furanyl can interconvert with 3-methylene-2-methyl-oxetane as intermediate. Decomposition of 4-penten-2oxy, formed by $\mathrm{C}-\mathrm{O} \beta$-scission of tetrahydro-2-methyl-4-furanyl, by $\mathrm{C}-\mathrm{C} \beta$-scission to acetaldehyde and allyl is favored over C-C $\beta$-scission to 3-butenal plus methyl, intramolecular hydrogen abstraction to 2-hydroxy-4-penten-3-yl and exo-intramolecular radical addition to 2methylene-4-methyl-oxetane. The latter radical is also formed by exo-intramolecular radical addition of the 2-vinyloxy-propyl radical, formed by C-C $\beta$-scission of tetrahydro-2-methyl-5furanyl. Hence, tetrahydro-2-methyl-5-furanyl and tetrahydro-2-methyl-4-furanyl can interconvert with 2-methylene-4-methyl-oxetane as intermediate.

At the investigated operating conditions, $\beta$-scission reactions of the radicals formed following ring opening of tetrahydro-2-methyl-2-furanyl, tetrahydro-2-methyl-3-furanyl, tetrahydro-2methyl-4-furanyl and tetrahydro-2-methyl-5-furanyl are kinetically favored over intramolecular hydrogen abstraction and radical addition reactions. Only in the case of 3-vinyloxy-propyl, which is formed by $\mathrm{C}-\mathrm{C} \beta$-scission of the 2-methylene-tetrahydrofuran radical, endo- 
intramolecular radical addition to tetrahydro-2-pyranyl is favored over $\mathrm{C}$-C $\beta$-scission to vinyloxy-methyl plus ethene below $1050 \mathrm{~K}$. Calculated rate coefficients of competing reactions are displayed as a function of temperature in Supplementary Material.

\section{Substitution of hydrogen atom on MTHF}

As will be discussed in 4.1, water yields are underpredicted in pyrolysis conditions. Hydrogen atom addition on the ring oxygen atom of MTHF forms 2-pentyl-5-ol, reaction 98. The latter radical can react by subsequent $\mathrm{C}-\mathrm{C} \beta$-scissions forming two ethene molecules plus hydroxyl radical. The calculated reaction rate coefficient for reaction 98 is five orders lowers than the competing hydrogen abstraction reactions. Therefore, this reaction path does not contribute significantly to hydroxyl radical and water formation.

\subsection{Base mechanism}

The mechanism developed for propene oxidation and combustion by Burke et al. served as reaction base [38, 39]. This model was developed hierarchically and has been validated for hydrogen, methane, ethane, ethene, propene, methanol, ethanol and acetaldehyde combustion. Note that the base mechanism is different compared to previously developed kinetic models by Tran et al. for tetrahydrofuran and tetrahydropyran pyrolysis and combustion [10, 35]. The change in base mechanism in this work is motivated by the relatively bad agreement of these models for tetrahydropyran and tetrahydrofuran laminar burning velocities. As discussed in the referred works, the cause of the observed discrepancies is probably related to the utilized base mechanism. 


\subsection{Secondary mechanism}

The third part of the developed kinetic model is a secondary mechanism which contains the reactions of species formed in the primary mechanism and for which no consumption routes are included in the base mechanism.

Submechanisms for tetrahydrofuran and tetrahydropyran pyrolysis and combustion were taken from recently developed kinetic models by Tran et al.[10, 35]. Isomerization of alkylated dihydrofurans were implemented as suggested by Dubnikova and Lifshitz [40]. Rate coefficients for reactions describing the decomposition of aldehydes and ketones, products detected in the premixed laminar low-pressure flames, were estimated using the EXGAS database [41].

Pathways to benzene were included in the developed kinetic model. Self-recombination of allyl radicals followed by hydrogen abstraction and addition of vinyl on 1,3-butadiene lead to 2,5hexadien-1-yl which can react to cyclohexen-3-yl by intramolecular radical addition. Subsequent dehydrogenation steps of cyclohexen-3-yl lead to benzene. Reaction rate coefficients were taken from Wang et al. [42, 43]. Recombination of cyclopentadienyl with methyl, followed by hydrogen abstraction and ring enlargement is another possible formation pathway for benzene. Reaction rate coefficients were taken from Green and coworkers [44, 45]. Reactions involving propargyl are known to be important for benzene formation in flames. Kinetics regarding selfrecombination of propargyl radicals and recombination of propargyl with allyl were taken from Georgievskii et al.[46] and Miller et al. [47]. 


\subsection{Thermochemistry and transport data}

Thermochemical data for species and radicals were taken from extensive databases whenever possible[48, 49]. Otherwise, this data was calculated using the software THERGAS [50] which is based on the group additivity method proposed by Benson [51].

Thermochemistry for MTHF was taken from the Third Millennium Thermochemical Database [48]. The enthalpy of formation at $298 \mathrm{~K}$ is $-225.1 \mathrm{~kJ} \mathrm{~mol}^{-1}$, which agrees well with the recommended value of $-225.4 \mathrm{~kJ} \mathrm{~mol}^{-1}$ by Simmie [14] and $-228.4 \mathrm{~kJ} \mathrm{~mol}^{-1}$ by Wijaya et al. [52].

Transport properties of species, for which no data is available from literature, were estimated using the RMG TransportDataEstimator [53].

\section{Results and discussion}

The pyrolysis results obtained in a flow reactor and combustion results obtained in low-pressure and atmospheric premixed flames are presented in this section. Comparisons of model simulations with the fuel-rich flames $(\phi=1.7)$ investigated by Moshammer et al. are presented in Supplementary Material.

\subsection{Thermal decomposition of MTHF in a tubular flow reactor}

\section{Experimental and simulated results}

An experimental dataset was obtained for the pyrolysis of MTHF in a tubular flow reactor, described in section 2.1. The pressure was kept constant at $0.17 \mathrm{MPa}$. MTHF and $\mathrm{N}_{2}$ inlet molar flow rates correspond to $1.6710^{-4}$ and $1.6710^{-3} \mathrm{~mol} \mathrm{~s}^{-1}$ respectively. The temperature was varied between 900 and $1100 \mathrm{~K}$. 
Besides hydrocarbons, several oxygenated products were detected in the reactor effluent, including $\mathrm{CO}, \mathrm{H}_{2} \mathrm{O}$, formaldehyde, acetaldehyde, ketene and 4-penten-1-ol. The majority of these species can be formed by typical radical chemistry, i.e. hydrogen abstraction from MTHF followed by $\beta$-scission, also see section 3.1. It is worthwhile to point out that several oxygenated species that are present in Table 2 were not detected. For example, vinyloxy-ethene can be formed through reaction 49 . However, the corresponding reaction rate is significantly slower than the rate of competing reaction 48 . The inability to detect vinyloxy-ethene is, thus, in agreement, with the computed rate coefficients.

Several hydrocarbons exhibit a maximum in their experimental mole fraction profile, such as propene, 1-butene and 1,3-butadiene. At high temperatures, secondary reactions that consume these species are known to be important. Such reactions can result in the formation of aromatics, evidenced by the experimentally-observed exponential increase of benzene.

Formaldehyde, acetaldehyde and ketene, also exhibit maxima in their mole fraction profile. These oxygenated molecules can be formed directly from MTHF by hydrogen abstraction and radical decomposition, also see Table 2. Above 1000K, their yield decreases and the oxygen atom mainly ends up in $\mathrm{CO}$.

At low temperature and conversion, the pyrolysis of MTHF has a relatively high selectivity towards 4-penten-1-ol, approximately $20 \%$ at $913 \mathrm{~K}$. The selectivity towards 4-penten-1-ol decreases at higher temperature and conversion. As 4-penten-1-ol has the same molecular formula as MTHF, i.e. $\mathrm{C}_{5} \mathrm{H}_{10} \mathrm{O}$, it cannot be formed through the hydrogen abstraction, $\beta$-scission reaction sequence. Instead, it can be formed through concerted decomposition of MTHF. The high experimental selectivity towards 4-penten-1-ol is in agreement with the relatively high 
computed rate coefficient of the pericyclic ring opening reaction of MTHF to 4-penten-1-ol, see Table 2, which dominates over other concerted unimolecular decomposition reactions.

Fig. 5 shows the experimental and model calculated mole fraction profiles of MTHF and a selected number of product species as a function of temperature. The calculated conversion profile agrees well with the experimental data. Furthermore, the model is in qualitative agreement with the experimental product profiles, i.e. it is able to capture the effect of temperature on mole fractions. The model is also in qualitative agreement with most product mole fraction profiles, the main exception being $\mathrm{H}_{2} \mathrm{O}$, see Fig. 5, which is underpredicted by a factor 4 and ketene, see Fig. 5 (I), which is overpredicted by a factor 2.

\section{Reaction path analysis}

A first reaction path analysis was performed with CHEMKIN-PRO using the plug flow reactor model and operating conditions corresponding to $\mathrm{P}=0.17 \mathrm{MPa}, \mathrm{T}=950 \mathrm{~K}-1000 \mathrm{~K}-1050 \mathrm{~K}$, $\mathrm{F}_{\mathrm{MTHF}}=1.6710^{-4} \mathrm{~mol} \mathrm{~s}^{-1}, \mathrm{~F}_{\mathrm{N} 2}=1.6710^{-3} \mathrm{~mol} \mathrm{~s}^{-1}$ at the inlet of the reactor.

At the inlet of the reactor, no radicals are present and MTHF can only decompose by unimolecular reactions, i.e. the unimolecular MTHF reaction rate equals the total MTHF reaction rate. The unimolecular decomposition of MTHF is dominated by the pericyclic ring opening reaction forming 4-penten-1-ol, where a hydrogen atom of the methyl group bridges to the ring oxygen, and C-C scission forming tetrahydro-2-furanyl plus methyl. The pericyclic ring opening reaction accounts for $74 \%, 61 \%$ and $48 \%$ of the total unimolecular decomposition rate at $950 \mathrm{~K}$, $1000 \mathrm{~K}$, and $1050 \mathrm{~K}$ respectively. C-C scission accounts for $26 \%, 38 \%, 51 \%$ of the total unimolecular decomposition rate at $950 \mathrm{~K}, 1000 \mathrm{~K}$, and $1050 \mathrm{~K}$ respectively. Scission of the ring bonds forming carbene and biradical intermediates and pericyclic ring opening reactions 
involving hydrogen atoms of ring carbon atoms contribute less than $1 \%$ of the total unimolecular decomposition rate. Note that latter reactions are significant in the pyrolysis of THF [8]. Hence, the presence of a methyl-group in MTHF completely changes the unimolecular decomposition paths compared to THF.

A second reaction path analysis was performed with CHEMKIN-PRO using the plug flow reactor model and operating conditions corresponding to $\mathrm{P}=0.17 \mathrm{MPa}, \mathrm{T}=950 \mathrm{~K}-1000 \mathrm{~K}$ $1050 \mathrm{~K}, \mathrm{~F}_{\mathrm{MTHF}}=1.6710^{-4} \mathrm{~mol} \mathrm{~s}^{-1}, \mathrm{~F}_{\mathrm{N} 2}=1.6710^{-3} \mathrm{~mol} \mathrm{~s}^{-1}$, conversion MTHF $=10 \%$. The main reaction pathways from MTHF are presented in Fig. 6.

In these conditions, a radical pool is established and MTHF is mostly consumed by hydrogen abstraction reactions. The pericyclic ring opening reaction accounts for $9 \%, 7 \%$ and $6 \%$ of the total MTHF consumption at 950K, 1000K, and 1050K respectively. C-C scission of the methyl side-group accounts for $2 \%, 4 \%$ and $6 \%$ of the total MTHF consumption at $950 \mathrm{~K}, 1000 \mathrm{~K}$, and 1050K respectively.

The main hydrogen abstracting species are methyl radicals and hydrogen atoms. Hydrogen abstraction from carbon atom 2 is favored, followed by carbon atoms 5, 4, 3 and the methyl carbon atom.

Tetrahydro-2-methyl-2-furanyl mainly reacts by $\mathrm{C}-\mathrm{O} \beta$-scission, forming 2-oxo-pent-5-yl. At $1000 \mathrm{~K}$, the rate coefficient is 200 times larger than the rate coefficient of the competing C-C $\beta$ scission and $2 \mathrm{E}+6$ times larger than the rate coefficient of the competing $\mathrm{C}-\mathrm{H} \beta$-scission to 5methyl-2,3-dihydrofuran, see Table 2. The 2-oxo-pent-5-yl radical can form ethene plus 2-oxopropyl by $\mathrm{C}-\mathrm{C} \beta$-scission. This path contributes for approximately $70 \%$ of the total ethene formation rate. 
Tetrahydro-2-methyl-5-furanyl mainly reacts by C-O $\beta$-scission, forming 1-oxo-pent-4-yl. Consumption of 1-oxo-pent-4-yl is dominated by $\mathrm{C}-\mathrm{C} \beta$-scission to propene plus vinoxy and intramolecular hydrogen abstraction to 1-oxo-pent-1-yl. The former path contributes for approximately $50 \%$ of the total propene formation rate. 1-oxo-pent-1-yl rapidly forms 1-butyl plus $\mathrm{CO}$ following $\mathrm{CO} \alpha$-scission. C-C $\beta$-scission of 1-butyl to ethene plus ethyl radical and C-H $\beta$-scission of ethyl to ethene plus hydrogen atom contribute for approximately $25 \%$ of the total ethene formation rate.

The other three MTHF-radicals, tetrahydro-2-methyl-3-furanyl, tetrahydro-2-methyl-4-furanyl and 2-methylene-tetrahydrofuran, are formed in lower amounts. Decomposition of tetrahydro-2methyl-4-furanyl and 2-methylene-tetrahydrofuran by C-O $\beta$-scission forms formaldehyde plus but-1-en-3-yl and formaldehyde plus but-1-en-4-yl respectively. Formaldehyde is almost exclusively formed by the latter two pathways, which is accurately predicted by the kinetic model. Decomposition of tetrahydro-2-methyl-4-furanyl by C-O $\beta$-scission is the main source of acetaldehyde, next to hydrogen abstraction by 2-oxo-ethyl from MTHF.

Water is formed by hydrogen abstraction of hydroxyl radicals. Hydroxyl is formed by several consumption pathways of 4-penten-1-ol. C-C scission of 4-penten-1-ol, forming allyl plus 2hydroxy-ethyl, and radical addition on the terminal carbon atom of the $\mathrm{C}=\mathrm{C}$ double bond followed by $\mathrm{C}-\mathrm{C} \beta$-scission contribute for approximately $90 \%$ of the total 4-penten-1-ol consumption. Both pathways form 2-hydroxy-ethyl which is the main source of hydroxyl radicals, through $\mathrm{C}-\mathrm{O} \beta$-scission forming ethene as second product. Water yields are highly sensitive to the formation of 4-penten-1-ol. The experimental yield of the latter molecule is underpredicted by the kinetic model, especially at the lowest investigated temperatures. As mentioned in 3.1, 4-penten-1-ol is formed by a concerted ring opening reaction of MTHF. 
Increasing the corresponding reaction rate coefficient would have a beneficial effect on the model performance regarding water and 4-penten-1-ol.

Ketene is formed by $\mathrm{C}-\mathrm{H} \beta$-scission of 2-oxo-ethyl and $\mathrm{C}-\mathrm{C} \beta$-scission of 2-oxo-propyl. The overprediction of oxygen selectivity towards ketene matches the underprediction of oxygen selectivity towards water. Note that both 2-oxo-ethyl and 2-oxo-propyl are formed by hydrogen abstraction from MTHF and subsequent $\beta$-scission reactions. Hence, increasing the fraction of MTHF that reacts by unimolecular decomposition would reduce the fraction of MTHF that reacts by hydrogen abstraction and, thus, reduce ketene yields.

Three important benzene formation paths were identified in the investigated pyrolysis conditions: (i) addition of vinyl on 1,3-butadiene to 1,5-hexadien-3-yl followed by intramolecular radical addition to cyclohexen-4-yl and dehydrogenation, (ii) recombination of 1,3-cyclopentadienyl with methyl followed by hydrogen abstraction and ring enlargement, (iii) recombination of allyl and propargyl to fulvene followed by hydrogen-assisted isomerization to benzene. These formation paths are depicted in Supplementary Material.

\subsection{Combustion of MTHF in low-pressure premixed flat flame}

\section{Experimental and simulated results}

The chemical structure of MTHF flames were investigated at three equivalences ratios, which are $\varphi=0.7,1.0$ and 1.3. Some 50 species were identified and quantified. Compared to the experimental pyrolysis results, a considerably higher number of oxygenated molecules were detected and quantified. Fig. 7, Fig. 8, Fig. 9 and Fig. 10 present mole fraction profiles of feed molecules and products as a function of distance above the burner. The selected products in these 
figures have high yields and/or are important intermediates according to reaction path analysis. Stereoisomers have been lumped in these figures.

MTHF, see Fig. 7, is completely consumed at a height of $2.0 \mathrm{~mm}$ above the burner [T $>1200 \mathrm{~K}]$. Model calculated mole fraction profiles of $\mathrm{CO}_{2}, \mathrm{H}_{2} \mathrm{O}, \mathrm{CO}$ and $\mathrm{H}_{2}$, see Fig. 7, agree well with experimental mole fraction profiles.

Experimental yields of most hydrocarbon products and oxygenated molecules have maxima at a height of approximately $2.0 \mathrm{~mm}$ above the burner.

The kinetic model is in qualitative agreement with the experimental data of all hydrocarbon products, see Fig. 7 and Fig. 8. As mentioned earlier, the volumetric flow rate of the unburned gas was constant for all equivalence ratios. At fuel-rich conditions $(\varphi=1.3)$, the operating conditions caused the flame to be relatively close to the burner; therefore, flame temperature and species profiles were significantly disturbed by the sampling probe resulting in a higher experimental error. For propene, 1-butene and 1,3-butadiene, model agreement deteriorates at higher equivalence ratios, underpredicting the experimental mole fraction profile. Interestingly, at the fuel-rich conditions $(\varphi=1.7)$ by Moshammer at al. [17], model calculated mole fraction profile for propene is in good agreement with the experimental data while 1-butene and 1,3butadiene yields are overpredicted, see Fig. 11.

Aldehydes, having between one and five carbon atoms, were detected in the reactor effluent. Note that the base mechanism and primary mechanism only contain chemistry that describes the formation and consumption of aldehydes between one and three carbon atoms. The obtained experimental data motivated the inclusion of chemistry that describes the formation and consumption of butanal, pentanal and pentenal in the secondary mechanism. Experimental and 
model calculated aldehyde mole fraction profiles are presented in Fig. 9. The model calculated peak in 2-butenal is approximately a factor 5 larger than experimental observations. A similar overprediction is observed for 2,3-dihydrofuran, see Fig. 10. 2,3-dihydrofuran rapidly isomerizes to cyclopropanecarboxaldehyde and 2-butenal $[10,17,54]$. In the modeling of low-pressure premixed tetrahydrofuran flames by Tran et al.[10], the same disagreement for 2-butenal and 2,3-dihydrofuran was observed. Note that in this work, reactions and associated rate coefficients for consumption of 2,3-dihydrofuran, 2-butenal and cyclopropanecarboxaldehyde were adopted from Tran et al. [10].

A second class of oxygenated molecules in the reactor effluent is ketones. Note that acetone was the only ketone measured experimentally in tetrahydrofuran premixed laminar flames and its maximum mole fraction is approximately a factor 10 lower than what is measured here, under comparable conditions [10]. The base mechanism and primary mechanism only contains chemistry that describes the formation and consumption of acetone and butanone. The obtained experimental data motivated the inclusion of chemistry that describes the formation and consumption of butenone and 2-pentanone in the secondary mechanism. The increased yield of ketones can be linked to several specific MTHF consumption pathways, which will be discussed in the following section. Model calculated mole fraction profiles are in relatively good agreement with experimental mole fraction profiles, see Fig. 10.

\section{Reaction path analysis and comparison with pyrolysis conditions}

A reaction path analysis was performed with CHEMKIN-PRO using the premixed laminar flame model at $\mathrm{P}=6.66 \mathrm{kPa}$ and $\varphi=1.0$. The reaction path analysis helps to identify the dominant product formation paths. This is presented in Fig. 12. 
As can be seen from Fig. 12, the MTHF consumption reactions in premixed laminar flames resemble those in pyrolysis. Obviously, the same radicals and molecules are formed following ring opening and hydrogen abstraction from MTHF and C-O/C-C $\beta$-scission of MTHF radicals. These formation paths will not be repeated in this section. Instead, this section will focus on the differences in reaction flux between flame and pyrolysis conditions.

Compared to pyrolysis, a higher fraction of MTHF is consumed by $\mathrm{C}-\mathrm{C}$ scission of the methyl side-group. The latter reaction has a high activation energy and therefor has a higher flux in the high temperature flames compared to the relatively low-temperature pyrolysis experiments. Ring opening to 4-penten-1-ol accounts for less than $1 \%$ of the total MTHF consumption at the conditions investigated in Fig. 12. 4-penten-1-ol is rapidly consumed, e.g. by scission of the weak allyl - 2-hydroxy-ethyl bond in 4-penten-1-ol. The peak in model calculated mole fraction profile is below $10 \mathrm{ppm}$, explaining why it was not possible to identify and quantify this species experimentally.

The majority of MTHF is consumed by hydrogen abstraction. Hydrogen atoms are the main hydrogen abstracting radicals, followed by hydroxyl. Hydrogen abstraction from MTHF by methyl, the main hydrogen abstracting radical in the pyrolysis conditions investigated in Fig. 6, is now insignificant. Methyl is mainly consumed by reaction with oxygen and recombination with other radicals. Methyl plus atomic oxygen to formaldehyde plus atomic hydrogen is the main source of formaldehyde at the reactor conditions of Fig. 12, rather than formation by decomposition of MTHF radicals.

Hydrogen abstraction from MTHF forming tetrahydro-2-methyl-2-furanyl is favored, but less pronounced compared to the pyrolysis conditions investigated in Fig. 6. The higher temperature 
in the MTHF flame and the high contribution of hydroxyl radicals to the total hydrogen abstraction rate decrease selectivity to tetrahydro-2-methyl-2-furanyl.

The presence of molecular oxygen and the augmented radical concentration in the MTHF flames, given the higher temperature and lower pressure, changes the consumption of primary radicals and molecules. This is especially the case for the resonantly stabilized radicals allyl, 2oxo-ethyl and 2-oxo-propyl. Consumption pathways of the latter 3 radicals are emphasized in Fig. 12.

The majority of allyl radicals reacts by recombination. Recombination with hydrogen atoms and methyl radicals are important allyl consumption routes. These paths accounts for $25 \%$ of the total propene formation and $90 \%$ of the total 1-butene formation, respectively, at the given conditions. Hydrogen abstraction from 1-butene and subsequent $\mathrm{C}-\mathrm{H} \beta$-scission is an important source of 1,3-butadiene. Hence, formation paths of propene, 1-butene and 1,3-butadiene, for which model disagreement increased with increasing equivalence ratio, are all linked to these allyl recombination reactions. Other allyl consumptions to products presented in Fig. 7, Fig. 8, Fig. 9 and Fig. 10 are allyl plus ethyl to 1-pentene, allyl plus atomic oxygen to acrolein plus atomic hydrogen, recombination of allyl plus hydroperoxy which eventually forms acrolein, a hydrogen atom and a hydroxyl radical following decomposition of the hydroperoxide [55].

The 2-oxo-ethyl radical is mainly formed by decomposition of the 2-methyl-5-furanyl radical. The 2-oxo-ethyl radical is resonantly stabilized and, thus, has a relatively long lifetime. It mainly forms methyl plus $\mathrm{CO}$ and ketene plus hydrogen atom [56], Recombination reactions with hydrogen atom, methyl, ethyl and allyl radicals form acetaldehyde, propanal, butanal and 4pentenal respectively, see Fig. 9. Comparison between experimental and model calculated mole fraction profiles for the larger aldehydes suggests that model agreement can be improved by 
modifying the rate coefficients for recombination, or rate coefficients of the competing 2-oxoethyl decomposition reactions.

The 2-oxo-propyl radical is formed by decomposition of the tetrahydro-2-methyl-2-furanyl radical. It mainly reacts by $\mathrm{C}$ - $\mathrm{C} \beta$-scission forming ketene and methyl, similar as in pyrolysis. Recombination with hydrogen, methyl and ethyl forms acetone, butanone and 2-pentanone respectively, see Fig. 10.

\subsection{Laminar burning velocities of MTHF at atmospheric pressure}

\section{Experimental and simulated results}

To our knowledge, no investigation on the adiabatic laminar burning velocities of MTHF in air has been published prior to the present study. Experimental data for the adiabatic laminar burning velocities of MTHF-air mixtures were measured on a flat flame burner at atmospheric pressure, with unburned gas temperatures ranging between 298 and $398 \mathrm{~K}$ and equivalence ratios ranging between 0.6 and 1.55.The obtained results are displayed in Fig. 13. These profiles exhibit maxima at $\varphi=1.1$, similar to most hydrocarbons and oxygenated molecules [57].

Model calculated laminar burning velocities are added to Fig. 13. Reasonable agreement is observed for all unburned gas temperatures and equivalence ratios. Model discrepancies become more pronounced at higher unburned gas temperatures. As discussed in section 3.2, the base mechanism of the developed kinetic model is the propene oxidation model by Burke et al. [39]. Interestingly, the latter model also has increasing disagreement with experimental laminar burning velocities for propene flames at higher unburned gas temperature.

The new developed model was also validated against tetrahydrofuran and tetrahydropyran laminar burning velocities $[10,35]$, given the change in base mechanism compared to previously 
published models, see section 3.2. These results can be found in Supplementary Material. The change in base mechanism results in an improved agreement with the experimental laminar burning velocities. Note that the developed model is also in good agreement with the experimental speciation data obtained in the referred works, which can also be found in Supplementary Material.

\section{Sensitivity analysis}

A sensitivity analysis with respect to laminar burning velocity was performed at an unburned gas temperature of $298 \mathrm{~K}$ and equivalence ratio of 1.1 . Such an analysis is able to identify reactions that influence laminar burning velocity most significantly. Selected results are presented in Fig. 14. A reaction with a positive sensitivity coefficient indicates that raising the associated preexponential factor increases the laminar burning velocity, a reaction with a negative sensitivity coefficient indicates that reducing the associated pre-exponential factor increases the laminar burning velocity.

Laminar burning velocities are mainly controlled by reactions of small species [57]. Also in this work, the chain branching reaction of molecular oxygen with a hydrogen atom forming atomic oxygen and a hydroxyl radical is the most sensitive reaction for laminar burning velocities. Note that this reaction is part of the base mechanism and rate coefficients are taken from the experimental study by Hong et al.[58]. The stated uncertainty is below 10\%. Other sensitive reactions involve the consumption and production of hydrogen atoms, as these can react with molecular oxygen through the aforementioned chain branching reaction. For example, decomposition of the formyl radical has a positive sensitivity coefficient as this produces a hydrogen atom while reaction of the formyl radical with a hydrogen atom to carbon monoxide 
and molecular hydrogen has a negative sensitivity coefficient as this consumes a hydrogen atom and a formyl radical, which could otherwise decompose forming a hydrogen atom.

Some reactions that are related to MTHF consumption are displayed in Fig. 14. As discussed previously, MTHF produces high yields of ketene via $\mathrm{C}-\mathrm{C} \beta$-scission of 2-oxo-propyl and $\mathrm{C}-\mathrm{H}$ $\beta$-scission of 2-oxo-ethyl. Ketene can be consumed by hydrogen abstraction by hydrogen atoms and by hydrogen addition forming 1-oxo-ethyl. The former reaction has a positive sensitivity coefficient as the resulting ketenyl react can react with molecular oxygen forming carbon monoxide, carbon dioxide plus a hydrogen atom [59] while the latter reaction has a negative sensitivity coefficient as 1 -oxo-ethyl forms a relatively unreactive methyl radical by $\mathrm{CO} \alpha$ scission, which can recombine with a hydrogen atom forming methane.

The recombination of allyl radical, which is formed by decomposition of the tetrahydro-2methyl-4-furanyl radical and by hydrogen abstraction from propene, with a hydrogen atom has negative sensitivity coefficient as it results in a decrease of radicals in the reactive system. Scission of MTHF to methyl plus tetrahydro-2-furanyl radicals has a positive sensitivity coefficient as it results in an increase of radicals in the reactive system.

Hydrogen abstraction from MTHF by hydrogen atoms forming tetrahydro-2-methyl-2-furanyl and tetrahydro-2-methyl-5-furanyl are displayed in Fig. 14. The former radical mainly decomposes to ethene while the latter radical mainly decomposes to propene. Hydrogen abstraction from ethene yields vinyl radicals, which may form hydrogen atoms upon $\mathrm{C}-\mathrm{H} \beta$ scission or lead to chain branching by reaction with molecular oxygen [60]. Consumption of propene by hydrogen abstraction creates unreactive allyl radicals.

\section{Comparison of adiabatic laminar burning velocity with tetrahydrofuran}


The adiabatic laminar burning velocities of tetrahydrofuran has been investigated using the same experimental setup and similar operating conditions [10]. Tetrahydrofuran exhibits a maximum in laminar burning velocity at $\varphi=1.1$, similar to MTHF. Laminar burning velocities of tetrahydrofuran are higher compared to MTHF, for example $43 \mathrm{~cm} / \mathrm{s}$ versus $39 \mathrm{~cm} / \mathrm{s}$ at $\varphi=1.1$ and $\mathrm{T}_{\text {initial }}=298 \mathrm{~K}[10]$.

Methyl substitution is known to reduce flame speeds in alkanes and cycloalkanes [57, 61]. In these hydrocarbons, this is considered to be mainly a kinetic effect due to an increase in methyl and propene formation. The latter two species affect hydrogen atom concentration, i.e. methyl radicals reduce flame speed by removing hydrogen atoms from the system through recombination while propene is consumed by hydrogen abstraction forming allyl which can recombine with hydrogen atoms. Note that recombination of hydrogen atoms with methyl and allyl radicals appear in the sensitivity analysis, i.e. Fig. 14. The concentration of propene is approximately two times higher in MTHF flames compared to THF flames under comparable conditions [10]. Furthermore, methyl formation rates are higher in MTHF flames compared to THF flames. Hence, the same kinetic effects are important in the investigated cyclic oxygenated components as in hydrocarbons for explaining the decrease in flame speeds.

\section{Conclusions}

This works presents new experimental data for the pyrolysis and combustion of MTHF obtained in a plug flow reactor and premixed laminar flames (flame structure and burning velocity measurements). The pyrolysis experimental data provides insight in the main MTHF consumption pathways and associated product spectrum. The number of detected oxygenated species in flames is substantially higher due to the presence of molecular oxygen. At similar 
conditions, a lower burning velocity is observed for MTHF than for previously studied saturated and unsaturated cyclic ethers.

The experimental data was interpreted using a newly developed kinetic model. The basis for the model is an existing, validated, propene oxidation model. Chemistry related to the decomposition of MTHF was either based on quantum chemical calculations or estimated by analogy with previous work regarding the pyrolysis and combustion of tetrahydrofuran and tetrahydropyran.

Model calculated and experimental data profiles are in reasonable agreement. The most important unimolecular decomposition reactions for MTHF are scission of the methyl group and concerted ring opening to 4-penten-1-ol. Scission of the ring bonds forming diradical and carbene species, important in the pyrolysis of THF, is negligible. As soon a radical pool is established, MTHF is mainly consumed by hydrogen abstraction reactions. Hydrogen abstraction from the carbon atoms $\alpha$ to the ring oxygen is favored, comparable to tetrahydrofuran and tetrahydropyran. At pyrolysis conditions, the decomposition pathways of the resulting MTHF radicals are able to explain the majority of the product spectrum. At combustion conditions, the same reaction paths are important. However, an increased importance for recombination reactions, given the higher radical concentration due to the higher temperature in flames compared to pyrolysis conditions, is observed. This is particularly the case for recombination reaction involving 2-oxo-ethyl and 2-oxo-propyl, which results in a variety of aldehydes and ketones.

\section{Acknowledgements}

The authors acknowledge the financial support from the Long Term Structural Methusalem Funding by the Flemish Government, the European Research Council under the European 
Union's Seventh Framework Programme (FP7/2007-2013) / ERC grant agreement n 290793, the Research Board of Ghent University (BOF) and the Fund for Scientific Research Flanders (FWO).The SBO proposals "Bioleum" and "Arboref" supported by the Institute for promotion of Innovation through Science and Technology in Flanders (IWT) are acknowledged. The work in the LRGP-Nancy was funded by the European Commission through the "Clean ICE" Advanced Research Grant of the European Research Council. Computational support was provided by the STEVIN Supercomputer Infrastructure at Ghent University, funded by Ghent University, the Flemish Supercomputer Center (VSC), the Hercules Foundation and the Flemish Government department EWI.

\section{Supplementary Material}

- Experimental data for the pyrolysis and combustion of 2-methyl-tetrahydrofuran

- Measured and simulated temperature profiles in premixed burner-stabilized flames

- Arrhenius plots of competing decomposition reaction of 2-methyl-tetrahydrofuran derived radicals

- Developed kinetic model

- Model comparison with premixed laminar flames obtained by Moshammer et al. 


\section{References}

[1] W. Yang, A. Sen, One-Step Catalytic Transformation of Carbohydrates and Cellulosic Biomass to 2,5-Dimethyltetrahydrofuran for Liquid Fuels, ChemSusChem 3 (2010) 597-603

[2] M. R. Grochowski, W. Yang, A. Sen, Mechanistic Study of a One-Step Catalytic Conversion of Fructose to 2,5-Dimethyltetrahydrofuran, Chem.-Eur. J. 18 (2012) 12363-12371

[3] J.-P. Lange, E. van der Heide, J. van Buijtenen, R. Price, Furfural-A Promising Platform for Lignocellulosic Biofuels, ChemSusChem 5 (2012) 150-166

[4] T. W. Rudolph, J. J. Thomas, NOx, NMHC and CO emissions from biomass derived gasoline extenders, Biomass 16 (1988) 33-49

[5] A. J. Janssen, F. W. Kremer, J. H. Baron, M. Muether, S. Pischinger, J. Klankermayer, Tailor-Made Fuels from Biomass for Homogeneous Low-Temperature Diesel Combustion, Energ. Fuel. 25 (2011) 4734-4744

[6] Y. Kar, H. Deveci, Importance of P-Series Fuels for Flexible-Fuel Vehicles (FFVs) and Alternative Fuels, Energy Sources, Part A: Recovery, Utilization, and Environmental Effects 28 (2006) 909-921

[7] W. R. Leppard, The Autoignition Chemistries of Octane-Enhancing Ethers and Cyclic Ethers: A Motored Engine Study, SAE Int. 100 (1991) 589-604

[8] M. Verdicchio, B. Sirjean, L. S. Tran, P.-A. Glaude, F. Battin-Leclerc, Unimolecular decomposition of tetrahydrofuran: Carbene vs. diradical pathways, P. Combust. Inst. 35 (2015) 533-541 
[9] A. Lifshitz, M. Bidani, S. Bidani, Thermal reactions of cyclic ethers at high temperatures.

Part 3. Pyrolysis of tetrahydrofuran behind reflected shocks, J. Phys. Chem. 90 (1986) 34223429

[10] L.-S. Tran, M. Verdicchio, F. Monge, R. C. Martin, R. Bounaceeur, B. Sirjean, P.-A. Glaude, M. U. Alzueta, F. Battin-Leclerc, An experimental and modeling study of the combustion of tetrahydrofuran, Combust. Flame 162 (2015) 1899-1918

[11] T. Kasper, A. Lucassen, W. Jasper Ahren, W. Li, R. Westmoreland Philip, K. KohseHöinghaus, B. Yang, J. Wang, A. Cool Terrill, N. Hansen, Identification of Tetrahydrofuran Reaction Pathways in Premixed Flames, Z. Phys. Chem. 225 (2011) 1237-1270

[12] P. Dagaut, M. McGuinness, J. M. Simmie, M. Cathonnet, The Ignition and Oxidation of Tetrahydrofuran: Experiments and Kinetic Modeling, Combust. Sci. Technol. 135 (1998) 3-29

[13] G. Vanhove, Y. Yu, M. A. Boumehdi, O. Frottier, O. Herbinet, P.-A. Glaude, F. BattinLeclerc, Experimental Study of Tetrahydrofuran Oxidation and Ignition in Low-Temperature Conditions, Energ. Fuel. 29 (2015) 6118-6125

[14] J. M. Simmie, Kinetics and Thermochemistry of 2,5-Dimethyltetrahydrofuran and Related Oxolanes: Next Next-Generation Biofuels, J. Phys. Chem. A 116 (2012) 4528-4538

[15] H. K. Chakravarty, R. X. Fernandes, Reaction Kinetics of Hydrogen Abstraction Reactions by Hydroperoxyl Radical from 2-Methyltetrahydrofuran and 2,5Dimethyltetrahydrofuran, J. Phys. Chem. A 117 (2013) 5028-5041 
[16] P. R. Parab, N. Sakade, Y. Sakai, R. X. Fernandes, K. A. Heufer, Theoretical Investigation of Intramolecular Hydrogen Shift Reactions in 3-Methyltetrahydrofuran (3-MTHF) Oxidation, J. Phys. Chem. A 119 (2015) 10917-10928

[17] K. Moshammer, S. Vranckx, H. K. Chakravarty, P. Parab, R. X. Fernandes, K. KohseHöinghaus, An experimental and kinetic modeling study of 2-methyltetrahydrofuran flames, Combust. Flame 160 (2013) 2729-2743

[18] M. R. Harper, K. M. Van Geem, S. P. Pyl, G. B. Marin, W. H. Green, Comprehensive reaction mechanism for n-butanol pyrolysis and combustion, Combust. Flame 158 (2011) 16-41

[19] M. Djokic, H.-H. Carstensen, K. M. Van Geem, G. B. Marin, The thermal decomposition of 2,5-dimethylfuran, P. Combust. Inst. 34 (2013) 251-258

[20] E. Pousse, P. A. Glaude, R. Fournet, F. Battin-Leclerc, A lean methane premixed laminar flame doped with components of diesel fuel: I. n-Butylbenzene, Combust. Flame 156 (2009) 954-974

[21] P. Dirrenberger, H. Le Gall, R. Bounaceur, O. Herbinet, P.-A. Glaude, A. Konnov, F. Battin-Leclerc, Measurements of Laminar Flame Velocity for Components of Natural Gas, Energ. Fuel. 25 (2011) 3875-3884

[22] L.-S. Tran, B. Sirjean, P.-A. Glaude, K. Kohse-Höinghaus, F. Battin-Leclerc, Influence of substituted furans on the formation of Polycyclic Aromatic Hydrocarbons in flames, P. Combust. Inst. 35 (2015) 1735-1743 
[23] P. Dirrenberger, P. A. Glaude, R. Bounaceur, H. Le Gall, A. P. da Cruz, A. A. Konnov, F. Battin-Leclerc, Laminar burning velocity of gasolines with addition of ethanol, Fuel 115 (2014) 162-169

[24] S. P. Pyl, C. M. Schietekat, K. M. Van Geem, M.-F. Reyniers, J. Vercammen, J. Beens, G. B. Marin, Rapeseed oil methyl ester pyrolysis: On-line product analysis using comprehensive two-dimensional gas chromatography, J. Chromatogr. A 1218 (2011) 3217-3223

[25] U. Bonne, T. Grewer, H. G. Wagner, Messungen in der Reaktionszone von Wasserstoff—Sauerstoff- und Methan—Sauerstoff-Flammen, Z. Phys. Chem. 26 (1960) 93-110

[26] L. P. H. de Goey, A. van Maaren, R. M. Quax, Stabilization of Adiabatic Premixed Laminar Flames on a Flat Flame Burner, Combust. Sci. Technol. 92 (1993) 201-207

[27] J. A. Montgomery, M. J. Frisch, J. W. Ochterski, G. A. Petersson, A complete basis set model chemistry. VI. Use of density functional geometries and frequencies, J. Chem. Phys. 110 (1999) 2822-2827

[28] M. J. Frisch, G. W. Trucks, H. B. Schlegel, G. E. Scuseria, M. A. Robb, J. R. Cheeseman, G. Scalmani, V. Barone, B. Mennucci, G. A. Petersson, H. Nakatsuji, M. Caricato, X. Li, H. P. Hratchian, A. F. Izmaylov, J. Bloino, G. Zheng, J. L. Sonnenberg, M. Hada, M. Ehara, K. Toyota, R. Fukuda, J. Hasegawa, M. Ishida, T. Nakajima, Y. Honda, O. Kitao, H. Nakai, T. Vreven, J. A. Montgomery, J. E. Peralta, F. Ogliaro, M. Bearpark, J. J. Heyd, E. Brothers, K. N. Kudin, V. N. Staroverov, R. Kobayashi, J. Normand, K. Raghavachari, A. Rendell, J. C. Burant, S. S. Iyengar, J. Tomasi, M. Cossi, N. Rega, J. M. Millam, M. Klene, J. E. Knox, J. B. Cross, V. Bakken, C. Adamo, J. Jaramillo, R. Gomperts, R. E. Stratmann, O. Yazyev, A. J. Austin, R. Cammi, C. Pomelli, J. W. Ochterski, R. L. Martin, K. Morokuma, V. G. Zakrzewski, G. A. Voth, 
P. Salvador, J. J. Dannenberg, S. Dapprich, A. D. Daniels, Farkas, J. B. Foresman, J. V. Ortiz, J. Cioslowski, D. J. Fox, in: Wallingford CT, 2009.

[29] A. L. L. East, L. Radom, An initio statistical thermodynamical models for the computation of third-law entropies, J. Chem. Phys. 106 (1997) 6655

[30] R. J. Kee, F. M. Rupley, J. A. Miller, M. E. Coltrin, J. F. Grcar, E. Meeks, H. K. Moffat, A. E. Lutz, G. Dixon-Lewis, M. D. Smooke, J. Warnatz, G. H. Evans, L. R. S., R. E. Mitchell, L. R. Petzold, W. C. Reynolds, M. Caracotsios, W. E. Stewart, P. Glarborg, C. Wang, O. Adigun, in: 15101 ed.; Reaction Design, Inc.: San Diego (CA), 2010.

[31] S. S. Merchant, E. F. Zanoelo, R. L. Speth, M. R. Harper, K. M. Van Geem, W. H. Green, Combustion and pyrolysis of iso-butanol: Experimental and chemical kinetic modeling study, Combust. Flame 160 (2013) 1907-1929

[32] Z. Wang, L. Ye, W. Yuan, L. Zhang, Y. Wang, Z. Cheng, F. Zhang, F. Qi, Experimental and kinetic modeling study on methylcyclohexane pyrolysis and combustion, Combust. Flame 161 (2014) 84-100

[33] K. Yasunaga, J. M. Simmie, H. J. Curran, T. Koike, O. Takahashi, Y. Kuraguchi, Y. Hidaka, Detailed chemical kinetic mechanisms of ethyl methyl, methyl tert-butyl and ethyl tertbutyl ethers: The importance of uni-molecular elimination reactions, Combust. Flame 158 (2011) 1032-1036

[34] A. Dean, J. Bozzelli, Combustion Chemistry of Nitrogen, in Gas-Phase Combustion Chemistry, W. C. Gardiner, Jr., (Ed.) Springer New York: 2000; pp 125-341. 
[35] L.-S. Tran, R. De Bruycker, H.-H. Carstensen, P.-A. Glaude, F. Monge, M. U. Alzueta,

R. C. Martin, F. Battin-Leclerc, K. M. Van Geem, G. B. Marin, Pyrolysis and combustion chemistry of tetrahydropyran: Experimental and modeling study, Combust. Flame 162 (2015) $4283-4303$

[36] M. K. Sabbe, A. Vandeputte, M.-F. Reyniers, M. Waroquier, G. B. Marin, Modeling the influence of resonance stabilization on the kinetics of hydrogen abstractions, Phys. Chem. Chem. Phys. 12 (2010) 1278-1298

[37] P. D. Paraskevas, M. K. Sabbe, M.-F. Reyniers, N. G. Papayannakos, G. B. Marin, Kinetic Modeling of $\alpha$-Hydrogen Abstractions from Unsaturated and Saturated Oxygenate Compounds by Carbon-Centered Radicals, ChemPhysChem 15 (2014) 1849-1866

[38] S. M. Burke, U. Burke, R. Mc Donagh, O. Mathieu, I. Osorio, C. Keesee, A. Morones, E. L. Petersen, W. Wang, T. A. DeVerter, M. A. Oehlschlaeger, B. Rhodes, R. K. Hanson, D. F. Davidson, B. W. Weber, C.-J. Sung, J. Santner, Y. Ju, F. M. Haas, F. L. Dryer, E. N. Volkov, E. J. K. Nilsson, A. A. Konnov, M. Alrefae, F. Khaled, A. Farooq, P. Dirrenberger, P.-A. Glaude, F. Battin-Leclerc, H. J. Curran, An experimental and modeling study of propene oxidation. Part 2: Ignition delay time and flame speed measurements, Combust. Flame 162 (2015) 296-314

[39] S. M. Burke, W. Metcalfe, O. Herbinet, F. Battin-Leclerc, F. M. Haas, J. Santner, F. L. Dryer, H. J. Curran, An experimental and modeling study of propene oxidation. Part 1: Speciation measurements in jet-stirred and flow reactors, Combust. Flame 161 (2014) 2765-2784 [40] F. Dubnikova, A. Lifshitz, Isomerization of 2,3-Dihydrofuran and 5-Methyl-2,3dihydrofuran: Quantum Chemical and Kinetics Calculations, J. Phys. Chem. A 106 (2002) 10261034 
[41] V. Warth, N. Stef, P. A. Glaude, F. Battin-Leclerc, G. Scacchi, G. M. Côme, ComputerAided Derivation of Gas-Phase Oxidation Mechanisms: Application to the Modeling of the Oxidation of n-Butane, Combust. Flame 114 (1998) 81-102

[42] K. Wang, S. M. Villano, A. M. Dean, Reactions of allylic radicals that impact molecular weight growth kinetics, Phys. Chem. Chem. Phys. 17 (2015) 6255-6273

[43] K. Wang, S. M. Villano, A. M. Dean, Fundamentally-based kinetic model for propene pyrolysis, Combust. Flame 162 (2015) 4456-4470

[44] S. Sharma, M. R. Harper, W. H. Green, Modeling of 1,3-hexadiene, 2,4-hexadiene and 1,4-hexadiene-doped methane flames: Flame modeling, benzene and styrene formation, Combust. Flame 157 (2010) 1331-1345

[45] S. Sharma, W. H. Green, Computed Rate Coefficients and Product Yields for c-C(5)H(5) + CH(3) -> Products, J. Phys. Chem. A 113 (2009) 8871-8882

[46] Y. Georgievskii, J. A. Miller, S. J. Klippenstein, Association rate constants for reactions between resonance-stabilized radicals: $\mathrm{C} 3 \mathrm{H} 3+\mathrm{C} 3 \mathrm{H} 3, \mathrm{C} 3 \mathrm{H} 3+\mathrm{C} 3 \mathrm{H} 5$, and $\mathrm{C} 3 \mathrm{H} 5+\mathrm{C} 3 \mathrm{H} 5$, Phys. Chem. Chem. Phys. 9 (2007) 4259-4268

[47] J. A. Miller, S. J. Klippenstein, Y. Georgievskii, L. B. Harding, W. D. Allen, A. C. Simmonett, Reactions between Resonance-Stabilized Radicals: Propargyl + Allyl, J. Phys. Chem. A 114 (2010) 4881-4890

[48] E. Goos, A. Burcat, B. Ruscic, Extended Third Millennium Thermodynamic Database for Combustion and Air-Pollution Use with Updates from Active Thermochemical Tables, 2014 
[49] P. D. Paraskevas, M. K. Sabbe, M.-F. Reyniers, N. G. Papayannakos, G. B. Marin, Group Additive Values for the Gas-Phase Standard Enthalpy of Formation, Entropy and Heat Capacity of Oxygenates, Chem.-Eur. J. 19 (2013) 16431-16452

[50] C. Muller, V. Michel, G. Scacchi, G. M. Come, THERGAS - A computer program for the evaluation of thermochemical data of molecules and free-radicals in the gas-phase, J. Chim. Phys. PCB 92 (1995) 1154-1178

[51] S. W. Benson, Thermochemical Kinetics: Methods for the Estimation of Thermochemical Data and Rate Parameters, John Wiley \& Sons, New York, 1976

[52] C. D. Wijaya, R. Sumathi, W. H. Green, Thermodynamic Properties and Kinetic Parameters for Cyclic Ether Formation from Hydroperoxyalkyl Radicals, J. Phys. Chem. A 107 (2003) 4908-4920

[53] C. W. Gao, J. W. Allen, W. H. Green, R. H. West, Reaction Mechanism Generator: Automatic construction of chemical kinetic mechanisms, Comput. Phys. Commun. 203 (2016) $212-225$

[54] A. Lifshitz, M. Bidani, Thermal reactions of cyclic ethers at high temperatures. 5. Pyrolysis of 2,3-dihydrofuran behind reflected shocks, The Journal of Physical Chemistry 93 (1989) 1139-1144 C. F. Goldsmith, S. J. Klippenstein, W. H. Green, Theoretical rate coefficients for allyl + HO2 and allyloxy decomposition, P. Combust. Inst. 33 (2011) 273-282 
[56] J. P. Senosiain, S. J. Klippenstein, J. A. Miller, Pathways and Rate Coefficients for the Decomposition of Vinoxy and Acetyl Radicals, The Journal of Physical Chemistry A 110 (2006) $5772-5781$

[57] E. Ranzi, A. Frassoldati, R. Grana, A. Cuoci, T. Faravelli, A. P. Kelley, C. K. Law, Hierarchical and comparative kinetic modeling of laminar flame speeds of hydrocarbon and oxygenated fuels, Prog. Energy Combust. Sci. 38 (2012) 468-501

[58] Z. Hong, D. F. Davidson, E. A. Barbour, R. K. Hanson, A new shock tube study of the H\&\#xa0;+\&\#xa0;O2\&\#xa0; $\rightarrow \& \# x a 0 ; O H \& \# x a 0 ;+\& \# x a 0 ; O$ reaction rate using tunable diode laser absorption of H2O near 2.5\&\#xa0; $\mu$ m, P. Combust. Inst. 33 (2011) 309-316

P. Zou, D. L. Osborn, On the mechanism of the $\mathrm{HCCO}+\mathrm{O} 2$ reaction: Probing multiple pathways to a single product channel, Phys. Chem. Chem. Phys. 6 (2004) 1697-1705

[60] C. F. Goldsmith, L. B. Harding, Y. Georgievskii, J. A. Miller, S. J. Klippenstein, Temperature and Pressure-Dependent Rate Coefficients for the Reaction of Vinyl Radical with Molecular Oxygen, J. Phys. Chem. A 119 (2015) 7766-7779

[61] F. Wu, A. P. Kelley, C. K. Law, Laminar flame speeds of cyclohexane and monoalkylated cyclohexanes at elevated pressures, Combust. Flame 159 (2012) 1417-1425

[62] K. P. Somers, J. M. Simmie, F. Gillespie, U. Burke, J. Connolly, W. K. Metcalfe, F. Battin-Leclerc, P. Dirrenberger, O. Herbinet, P. A. Glaude, H. J. Curran, A high temperature and atmospheric pressure experimental and detailed chemical kinetic modelling study of 2-methyl furan oxidation, P. Combust. Inst. 34 (2013) 225-232 
[63] K. P. Somers, J. M. Simmie, F. Gillespie, C. Conroy, G. Black, W. K. Metcalfe, F. Battin-Leclerc, P. Dirrenberger, O. Herbinet, P.-A. Glaude, P. Dagaut, C. Togbé, K. Yasunaga, R. X. Fernandes, C. Lee, R. Tripathi, H. J. Curran, A comprehensive experimental and detailed chemical kinetic modelling study of 2,5-dimethylfuran pyrolysis and oxidation, Combust. Flame $160(2013) 2291-2318$ 
Table 1 Operating conditions for MTHF flames and pyrolysis

\begin{tabular}{|c|c|c|c|c|c|c|c|c|}
\hline \multirow{4}{*}{$\begin{array}{l}\text { Low-pressure } \\
\text { premixed } \\
\text { flame }\end{array}$} & $\varphi$ & $\begin{array}{c}\mathbf{F}_{\mathrm{MTHF}}^{0} \\
\left(\mathrm{~mol} \mathrm{~s}^{-1}\right)\end{array}$ & $\begin{array}{c}\mathbf{F}_{\mathbf{O 2}}^{0} \\
\left(\mathrm{~mol} \mathrm{~s}^{-1}\right)\end{array}$ & $\begin{array}{c}\mathbf{F}_{\mathrm{Ar}}^{0} \\
\left(\mathrm{~mol} \mathrm{~s}^{-1}\right)\end{array}$ & $\mathbf{P}(\mathbf{k P a})$ & $\mathrm{C} / \mathrm{O}$ & $\mathbf{x}_{\mathbf{0}, \text { diluent }}$ & $\begin{array}{l}\text { Flow velocity at } \\
T=333 K\left(\mathrm{~cm} \mathrm{~s}^{-1}\right)\end{array}$ \\
\hline & 0.7 & $1.15 \mathrm{E}-04$ & $1.15 \mathrm{E}-03$ & $3.29 \mathrm{E}-03$ & 6.7 & 0.24 & 0.72 & 67 \\
\hline & 1 & $1.39 \mathrm{E}-04$ & $9.74 \mathrm{E}-04$ & $3.45 \mathrm{E}-03$ & 6.7 & 0.33 & 0.76 & 67 \\
\hline & 1.3 & $2.02 \mathrm{E}-04$ & $1.09 \mathrm{E}-03$ & $3.27 \mathrm{E}-03$ & 6.7 & 0.42 & 0.72 & 67 \\
\hline \multirow{2}{*}{\multicolumn{4}{|c|}{ Atmospheric premixed laminar flame }} & \multicolumn{2}{|c|}{$\varphi$} & $\mathbf{P}(\mathbf{k P a})$ & \multicolumn{2}{|c|}{$\mathbf{T}_{\text {unburned gas }}(\mathbf{K})$} \\
\hline & & & & \multicolumn{2}{|c|}{$0.60-1.55$} & 101.3 & \multicolumn{2}{|r|}{$298-398$} \\
\hline \multirow[t]{2}{*}{ Flow reactor } & $\varphi$ & $\begin{array}{l}\mathrm{F}_{\mathrm{MTHF}}^{0} \\
\left(\mathrm{~mol} \mathrm{~s}^{-1}\right)\end{array}$ & $\begin{array}{c}\mathrm{F}_{\mathrm{O} 2}^{0} \\
\left(\mathrm{~mol} \mathrm{~s}^{-1}\right)\end{array}$ & $\begin{array}{c}\mathrm{F}_{\mathrm{N} 2}^{0} \\
\left(\mathrm{~mol} \mathrm{~s}^{-1}\right)\end{array}$ & $\mathbf{P}(\mathbf{k P a})$ & $\mathrm{C} / \mathrm{O}$ & $\mathbf{x}_{\mathbf{0} \text {,diluent }}$ & T-range (K) \\
\hline & $\infty$ & $1.68 \mathrm{E}-04$ & $0.00 \mathrm{E}+00$ & $1.67 \mathrm{E}-03$ & 170 & 5.00 & 0.91 & $913-1073$ \\
\hline
\end{tabular}


Table 2 Primary mechanism of the high-temperature pyrolysis and oxidation of MTHF. The rate coefficients are given $\left(k=A T^{n} \exp \left(-E_{a} / R T\right)\right)$ in $~^{3}$, mol, $s, k J$ units

\begin{tabular}{|c|c|c|c|c|c|c|}
\hline Nr. & Reaction & $\mathbf{A}$ & $\mathbf{n}$ & Ea & $\begin{array}{c}\mathbf{k} \\
(1000 K) \\
\end{array}$ & Comment \\
\hline & C-H and methyl scission & & & & & \\
\hline 1 & $\mathrm{C} \bullet \mathrm{cy}(\mathrm{COCCC})+\mathrm{H} \rightarrow \mathrm{Ccy}(\mathrm{COCCC})$ & $1.0 \mathrm{E}+08$ & 0.0 & 0.0 & $1.0 \mathrm{E}+08$ & $\mathrm{a}$ \\
\hline 2 & $\mathrm{Ccy}(\mathrm{C} \cdot \mathrm{OCCC})+\mathrm{H} \rightarrow \mathrm{Ccy}(\mathrm{COCCC})$ & $1.0 \mathrm{E}+08$ & 0.0 & 0.0 & $1.0 \mathrm{E}+08$ & $\mathrm{a}$ \\
\hline 3 & $\mathrm{Ccy}(\mathrm{COC} \cdot \mathrm{CC})+\mathrm{H} \rightarrow \mathrm{Ccy}(\mathrm{COCCC})$ & $1.0 \mathrm{E}+08$ & 0.0 & 0.0 & $1.0 \mathrm{E}+08$ & $\mathrm{a}$ \\
\hline 4 & $\mathrm{Ccy}(\mathrm{COCC} \cdot \mathrm{C})+\mathrm{H} \rightarrow \mathrm{Ccy}(\mathrm{COCCC})$ & $1.0 \mathrm{E}+08$ & 0.0 & 0.0 & $1.0 \mathrm{E}+08$ & $\mathrm{a}$ \\
\hline 5 & $\mathrm{Ccy}(\mathrm{COCCC} \bullet)+\mathrm{H} \rightarrow \mathrm{Ccy}(\mathrm{COCCC})$ & $1.0 \mathrm{E}+08$ & 0.0 & 0.0 & $1.0 \mathrm{E}+08$ & $\mathrm{a}$ \\
\hline \multirow[t]{2}{*}{6} & $\mathrm{cy}(\mathrm{OC} \cdot \mathrm{CCC})+\mathrm{CH}_{3} \rightarrow \mathrm{Ccy}(\mathrm{COCCC})$ & $1.0 \mathrm{E}+07$ & 0.0 & 0.0 & $1.0 \mathrm{E}+07$ & $\mathrm{a}$ \\
\hline & Carbene and biradical pathways & & & & & \\
\hline \multirow[t]{4}{*}{7} & $\mathrm{Ccy}(\mathrm{COCCC}) \rightarrow \mathrm{C}=\mathrm{CCOCC}$ & $1.4 \mathrm{E}+81$ & -19.5 & 529.5 & $1.0 \mathrm{E}-05$ & $\mathrm{~b}, 0.01 \mathrm{~atm}$ \\
\hline & & $5.2 \mathrm{E}+65$ & -14.8 & 501.0 & $1.3 \mathrm{E}-05$ & $\mathrm{~b}, 0.1 \mathrm{~atm}$ \\
\hline & & $4.8 \mathrm{E}+49$ & -10.1 & 467.3 & $1.3 \mathrm{E}-05$ & $\mathrm{~b}, 1 \mathrm{~atm}$ \\
\hline & & $9.9 \mathrm{E}+33$ & -5.5 & 430.2 & $1.3 \mathrm{E}-05$ & b, 10atm \\
\hline \multirow[t]{4}{*}{8} & $\mathrm{Ccy}(\mathrm{COCCC}) \rightarrow \mathrm{C}=\mathrm{CC}(\mathrm{C}) \mathrm{OC}$ & $1.4 \mathrm{E}+81$ & -19.5 & 529.5 & $1.0 \mathrm{E}-05$ & $\mathrm{~b}, 0.01 \mathrm{~atm}$ \\
\hline & & $5.2 \mathrm{E}+65$ & -14.8 & 501.0 & $1.3 \mathrm{E}-05$ & $\mathrm{~b}, 0.1 \mathrm{~atm}$ \\
\hline & & $4.8 \mathrm{E}+49$ & -10.1 & 467.3 & $1.3 \mathrm{E}-05$ & $\mathrm{~b}, 1 \mathrm{~atm}$ \\
\hline & & $9.9 \mathrm{E}+33$ & -5.5 & 430.2 & $1.3 \mathrm{E}-05$ & b, 10atm \\
\hline \multirow[t]{4}{*}{9} & $\mathrm{Ccy}(\mathrm{COCCC}) \rightarrow \mathrm{C}=\mathrm{COC}(\mathrm{C}) \mathrm{C}$ & $3.6 \mathrm{E}+82$ & -19.9 & 535.9 & $1.0 \mathrm{E}-05$ & $\mathrm{~b}, 0.01 \mathrm{~atm}$ \\
\hline & & $2.7 \mathrm{E}+65$ & -14.7 & 502.7 & $1.3 \mathrm{E}-05$ & $\mathrm{~b}, 0.1 \mathrm{~atm}$ \\
\hline & & $1.8 \mathrm{E}+51$ & -10.4 & 474.9 & $1.3 \mathrm{E}-05$ & $\mathrm{~b}, 1 \mathrm{~atm}$ \\
\hline & & $7.8 \mathrm{E}+34$ & -5.7 & 436.3 & $1.3 \mathrm{E}-05$ & $\mathrm{~b}, 10 \mathrm{~atm}$ \\
\hline \multirow[t]{4}{*}{10} & $\mathrm{Ccy}(\mathrm{COCCC}) \rightarrow \mathrm{C}=\mathrm{C}(\mathrm{C}) \mathrm{OCC}$ & $3.6 \mathrm{E}+82$ & -19.9 & 535.9 & $1.0 \mathrm{E}-05$ & $\mathrm{~b}, 0.01 \mathrm{~atm}$ \\
\hline & & $2.7 \mathrm{E}+65$ & -14.7 & 502.7 & $1.3 \mathrm{E}-05$ & $\mathrm{~b}, 0.1 \mathrm{~atm}$ \\
\hline & & $1.8 \mathrm{E}+51$ & -10.4 & 474.9 & $1.3 \mathrm{E}-05$ & $\mathrm{~b}, 1 \mathrm{~atm}$ \\
\hline & & $7.8 \mathrm{E}+34$ & -5.7 & 436.3 & $1.3 \mathrm{E}-05$ & $\mathrm{~b}, 10 \mathrm{~atm}$ \\
\hline \multirow[t]{4}{*}{11} & $\mathrm{Ccy}(\mathrm{COCCC}) \rightarrow \mathrm{CCCCCHO}$ & $3.9 \mathrm{E}+75$ & -17.9 & 493.2 & $1.1 \mathrm{E}-04$ & $\mathrm{~b}, 0.01 \mathrm{~atm}$ \\
\hline & & $2.6 \mathrm{E}+61$ & -13.7 & 464.0 & $1.1 \mathrm{E}-04$ & $\mathrm{~b}, 0.1 \mathrm{~atm}$ \\
\hline & & $6.6 \mathrm{E}+46$ & -9.4 & 430.6 & $1.1 \mathrm{E}-04$ & $\mathrm{~b}, 1 \mathrm{~atm}$ \\
\hline & & $1.1 \mathrm{E}+35$ & -6.0 & 401.8 & $1.1 \mathrm{E}-04$ & b, 10atm \\
\hline \multirow[t]{4}{*}{12} & $\mathrm{Ccy}(\mathrm{COCCC}) \rightarrow \mathrm{CCCC}(=\mathrm{O}) \mathrm{C}$ & $3.9 \mathrm{E}+75$ & -17.9 & 493.2 & $1.1 \mathrm{E}-04$ & $\mathrm{~b}, 0.01 \mathrm{~atm}$ \\
\hline & & $2.6 \mathrm{E}+61$ & -13.7 & 464.0 & $1.1 \mathrm{E}-04$ & $\mathrm{~b}, 0.1 \mathrm{~atm}$ \\
\hline & & $6.6 \mathrm{E}+46$ & -9.4 & 430.6 & $1.1 \mathrm{E}-04$ & $\mathrm{~b}, 1 \mathrm{~atm}$ \\
\hline & & $1.1 \mathrm{E}+35$ & -6.0 & 401.8 & $1.1 \mathrm{E}-04$ & $\mathrm{~b}, 10 \mathrm{~atm}$ \\
\hline \multirow[t]{4}{*}{13} & $\mathrm{Ccy}(\mathrm{COCCC}) \rightarrow \mathrm{CC}=\mathrm{CCCOH}$ & $5.1 \mathrm{E}+72$ & -17.0 & 484.2 & $2.1 \mathrm{E}-04$ & $\mathrm{~b}, 0.01 \mathrm{~atm}$ \\
\hline & & $7.8 \mathrm{E}+57$ & -12.6 & 454.4 & $2.2 \mathrm{E}-04$ & $\mathrm{~b}, 0.1 \mathrm{~atm}$ \\
\hline & & $1.7 \mathrm{E}+41$ & -7.7 & 416.1 & $2.2 \mathrm{E}-04$ & $\mathrm{~b}, 1 \mathrm{~atm}$ \\
\hline & & $3.7 \mathrm{E}+27$ & -3.7 & 383.0 & $2.2 \mathrm{E}-04$ & $\mathrm{~b}, 10 \mathrm{~atm}$ \\
\hline \multirow[t]{4}{*}{14} & $\mathrm{Ccy}(\mathrm{COCCC}) \rightarrow \mathrm{C}=\mathrm{CCC}(\mathrm{C}) \mathrm{OH}$ & $5.1 \mathrm{E}+72$ & -17.0 & 484.2 & $2.1 \mathrm{E}-04$ & $\mathrm{~b}, 0.01 \mathrm{~atm}$ \\
\hline & & $7.8 \mathrm{E}+57$ & -12.6 & 454.4 & $2.2 \mathrm{E}-04$ & $\mathrm{~b}, 0.1 \mathrm{~atm}$ \\
\hline & & $1.7 \mathrm{E}+41$ & -7.7 & 416.1 & $2.2 \mathrm{E}-04$ & $\mathrm{~b}, 1 \mathrm{~atm}$ \\
\hline & & $3.7 \mathrm{E}+27$ & -3.7 & 383.0 & $2.2 \mathrm{E}-04$ & $\mathrm{~b}, 10 \mathrm{~atm}$ \\
\hline \multirow[t]{4}{*}{15} & $\mathrm{Ccy}(\mathrm{COCCC}) \rightarrow \mathrm{CH}_{2} \mathrm{O}+\mathrm{C}=\mathrm{CCC}$ & $5.1 \mathrm{E}+67$ & -15.5 & 471.8 & $3.2 \mathrm{E}-04$ & $\mathrm{~b}, 0.01 \mathrm{~atm}$ \\
\hline & & $5.8 \mathrm{E}+50$ & -10.4 & 439.1 & $3.4 \mathrm{E}-04$ & $\mathrm{~b}, 0.1 \mathrm{~atm}$ \\
\hline & & $2.7 \mathrm{E}+35$ & -5.8 & 409.1 & 4.2E-04 & $\mathrm{b}, 1 \mathrm{~atm}$ \\
\hline & & $1.1 \mathrm{E}+26$ & -3.0 & 379.9 & $2.3 \mathrm{E}-04$ & b, 10atm \\
\hline
\end{tabular}




\section{Concerted ring opening}

$19 \mathrm{Ccy}(\mathrm{COCCC}) \rightarrow \mathrm{C}=\mathrm{CCCCOH}$

$20 \mathrm{Ccy}(\mathrm{COCCC}) \rightarrow \mathrm{CC}=\mathrm{CCCOH}$

$21 \mathrm{Ccy}(\mathrm{COCCC}) \rightarrow \mathrm{C}=\mathrm{CCC}(\mathrm{C}) \mathrm{OH}$

\section{Hydrogen abstraction}

\section{by $H$}

$22 \mathrm{Ccy}(\mathrm{COCCC})+\mathrm{H} \rightarrow \mathrm{Ccy}(\mathrm{COC} \cdot \mathrm{CC})+\mathrm{H}_{2}$

$23 \mathrm{Ccy}(\mathrm{COCCC})+\mathrm{H} \rightarrow \mathrm{Ccy}(\mathrm{COCC} \cdot \mathrm{C})+\mathrm{H}_{2}$

$24 \mathrm{Ccy}(\mathrm{COCCC})+\mathrm{H} \rightarrow \mathrm{Ccy}(\mathrm{COCCC} \bullet)+\mathrm{H}_{2}$

$25 \mathrm{Ccy}(\mathrm{COCCC})+\mathrm{H} \rightarrow \mathrm{Ccy}(\mathrm{C} \cdot \mathrm{OCCC})+\mathrm{H}_{2}$

\section{$\mathrm{Ccy}(\mathrm{COCCC})+\mathrm{H} \rightarrow \mathrm{C} \bullet \mathrm{cy}(\mathrm{COCCC})+\mathrm{H}_{2}$} by $\mathrm{CH} 3$

$\mathrm{Ccy}(\mathrm{COCCC})+\mathrm{CH}_{3} \rightarrow \mathrm{Ccy}(\mathrm{COC} \cdot \mathrm{CC})+\mathrm{CH}_{4}$ $\mathrm{Ccy}(\mathrm{COCCC})+\mathrm{CH}_{3} \rightarrow \mathrm{Ccy}(\mathrm{COCC} \cdot \mathrm{C})+\mathrm{CH}_{4}$ $\mathrm{Ccy}(\mathrm{COCCC})+\mathrm{CH}_{3} \rightarrow \mathrm{Ccy}(\mathrm{COCCC} \bullet)+\mathrm{CH}_{4}$ $\mathrm{Ccy}(\mathrm{COCCC})+\mathrm{CH}_{3} \rightarrow \mathrm{Ccy}(\mathrm{C} \cdot \mathrm{OCCC})+\mathrm{CH}_{4}$ $\mathrm{Ccy}(\mathrm{COCCC})+\mathrm{CH}_{3} \rightarrow \mathrm{C} \bullet \mathrm{cy}(\mathrm{COCCC})+\mathrm{CH}_{4}$ by $\mathrm{OH}$

$\mathrm{Ccy}(\mathrm{COCCC})+\mathrm{OH} \rightarrow \mathrm{Ccy}(\mathrm{COC} \cdot \mathrm{CC})+\mathrm{H}_{2} \mathrm{O}$ $\mathrm{Ccy}(\mathrm{COCCC})+\mathrm{OH} \rightarrow \mathrm{Ccy}(\mathrm{COCC} \cdot \mathrm{C})+\mathrm{H}_{2} \mathrm{O}$ $\mathrm{Ccy}(\mathrm{COCCC})+\mathrm{OH} \rightarrow \mathrm{Ccy}(\mathrm{COCCC} \cdot)+\mathrm{H}_{2} \mathrm{O}$ $\mathrm{Ccy}(\mathrm{COCCC})+\mathrm{OH} \rightarrow \mathrm{Ccy}(\mathrm{C} \cdot \mathrm{OCCC})+\mathrm{H}_{2} \mathrm{O}$ $\mathrm{Ccy}(\mathrm{COCCC})+\mathrm{OH} \rightarrow \mathrm{C} \bullet \mathrm{cy}(\mathrm{COCCC})+\mathrm{H}_{2} \mathrm{O}$ by $O$

$$
\mathrm{Ccy}(\mathrm{COCCC})+\mathrm{O} \rightarrow \mathrm{Ccy}(\mathrm{COC} \cdot \mathrm{CC})+\mathrm{OH}
$$
$\mathrm{Ccy}(\mathrm{COCCC})+\mathrm{O} \rightarrow \mathrm{Ccy}(\mathrm{COCC} \cdot \mathrm{C})+\mathrm{OH}$ $\mathrm{Ccy}(\mathrm{COCCC})+\mathrm{O} \rightarrow \mathrm{Ccy}(\mathrm{COCCC} \bullet)+\mathrm{OH}$ $\mathrm{Ccy}(\mathrm{COCCC})+\mathrm{O} \rightarrow \mathrm{Ccy}(\mathrm{C} \cdot \mathrm{OCCC})+\mathrm{OH}$ $\mathrm{Ccy}(\mathrm{COCCC})+\mathrm{O} \rightarrow \mathrm{C} \cdot \mathrm{cy}(\mathrm{COCCC})+\mathrm{OH}$ by $\mathrm{HO} 2$

$\mathrm{Ccy}(\mathrm{COCCC})+\mathrm{HO}_{2} \rightarrow \mathrm{Ccy}(\mathrm{COC} \cdot \mathrm{CC})+\mathrm{H}_{2} \mathrm{O}_{2}$ $\mathrm{Ccy}(\mathrm{COCCC})+\mathrm{HO}_{2} \rightarrow \mathrm{Ccy}(\mathrm{COCC} \cdot \mathrm{C})+\mathrm{H}_{2} \mathrm{O}_{2}$ $\mathrm{Ccy}(\mathrm{COCCC})+\mathrm{HO}_{2} \rightarrow \mathrm{Ccy}(\mathrm{COCCC} \bullet)+\mathrm{H}_{2} \mathrm{O}_{2}$ $\mathrm{Ccy}(\mathrm{COCCC})+\mathrm{HO}_{2} \rightarrow \mathrm{Ccy}(\mathrm{C} \cdot \mathrm{OCCC})+\mathrm{H}_{2} \mathrm{O}_{2}$ $\mathrm{Ccy}(\mathrm{COCCC})+\mathrm{HO}_{2} \rightarrow \mathrm{C} \cdot \mathrm{cy}(\mathrm{COCCC})+\mathrm{H}_{2} \mathrm{O}_{2}$ $M T H F$ radical decomposition $\underline{\mathrm{Ccy}(\mathrm{COC} \cdot \mathrm{CC})}$

$$
\mathrm{Ccy}(\mathrm{COC} \cdot \mathrm{CC}) \rightarrow \mathrm{C}=\mathrm{COCC} 2 \bullet
$$

$5.1 \mathrm{E}+67$

$5.8 \mathrm{E}+50$

$-15.5$

471.8

3.2E-04

$439.1 \quad 3.4 \mathrm{E}-04$

$2.7 \mathrm{E}+35$

$-5.8$

409.1

4.2E-04

$1.1 \mathrm{E}+26$

$-3.0$

379.9

$2.3 \mathrm{E}-04$

$2.5 \mathrm{E}+91 \quad-22.3$

587.9

$5.0 \mathrm{E}-07$

$2.6 \mathrm{E}+81$

$-19.1$

$9.3 \mathrm{E}+64$

$-14.1$

579.3

9.6E-07

$549.4 \quad 1.2 \mathrm{E}-06$

$1.3 \mathrm{E}+46$

$-8.5$

507.5

$1.2 \mathrm{E}-06$

$587.9 \quad 5.0 \mathrm{E}-07$

.5E+91

579.3

$9.6 \mathrm{E}-07$

$9.3 \mathrm{E}+64$

$1.3 \mathrm{E}+46$

$-8.5$

507.5

$1.2 \mathrm{E}-06$

$1.2 \mathrm{E}-06$

$1.1 \mathrm{E}+05$

2.3

248.5

8.5E-02

$1.0 \mathrm{E}+12$

0.6

342.6

$6.7 \mathrm{E}-05$

$1.0 \mathrm{E}+12$

0.6

342.6

6.7E-05

$3.3 \mathrm{E}+01$
$1.1 \mathrm{E}+01$
$1.0 \mathrm{E}+01$
$1.7 \mathrm{E}+02$
$4.2 \mathrm{E}+01$

$4.7 \mathrm{E}-04$
$3.2 \mathrm{E}-04$
$2.6 \mathrm{E}-04$
$3.9 \mathrm{E}-04$
$5.0 \mathrm{E}-04$

$2.4 \mathrm{E}+00$
$2.4 \mathrm{E}+00$
$2.4 \mathrm{E}+00$
$1.2 \mathrm{E}+00$
$3.6 \mathrm{E}+00$

1.9

13.8

$2.6 \mathrm{E}+06$

$23.9 \quad 7.2 \mathrm{E}+05$

$25.1 \quad 5.6 \mathrm{E}+05$

$9.2 \quad 6.6 \mathrm{E}+06$

$39.3 \quad 2.8 \mathrm{E}+05$

$27.6 \quad 1.2 \mathrm{E}+04$

$34.3 \quad 5.5 \mathrm{E}+03$

$35.6 \quad 3.9 \mathrm{E}+03$

$22.2 \quad 1.5 \mathrm{E}+04$

$45.6 \quad 2.4 \mathrm{E}+03$

$-12.3 \quad 1.1 \mathrm{E}+07$

$-2.7 \quad 3.3 \mathrm{E}+06$

$-0.4 \quad 2.5 \mathrm{E}+06$

$-13.9$

7.2

$6.4 \mathrm{E}+06$

$1.5 \mathrm{E}+06$

\section{$3.4 \mathrm{E}+02$}

$3.4 \mathrm{E}+02$

$3.4 \mathrm{E}+02$

$1.7 \mathrm{E}+02$

$5.1 \mathrm{E}+02$

1.5

$-0.3$

$1.1 \mathrm{E}+07$

$14.0 \quad 2.0 \mathrm{E}+06$

$17.5 \quad 1.3 \mathrm{E}+06$

$-2.8 \quad 7.5 \mathrm{E}+06$

$28.9 \quad 5.0 \mathrm{E}+05$

7.8E-06

7.2E- 08

$1.2 \mathrm{E}-06$

6.5E-05

1.7E-04

3.5

33.0

$5.7 \mathrm{E}+03$

$48.0 \quad 5.5 \mathrm{E}+02$

$50.9 \quad 3.8 \mathrm{E}+02$

$26.8 \quad 1.7 \mathrm{E}+04$

$\begin{array}{lll}3.5 & 71.5 & 7.9 \mathrm{E}+02\end{array}$

$4.6 \mathrm{E}+11$

\section{c}

b

b

$\mathrm{b}, 0.01 \mathrm{~atm}$

b, $0.1 \mathrm{~atm}$

b, 1atm

b, 10atm

b, $0.01 \mathrm{~atm}$

b, $0.1 \mathrm{~atm}$

b, $1 \mathrm{~atm}$

b, 10atm

b, $0.01 \mathrm{~atm}$

b, $0.1 \mathrm{~atm}$

b, 1atm

b, 10atm

b




\begin{tabular}{|c|c|c|c|c|c|c|}
\hline 48 & $\mathrm{C}=\mathrm{COCC} 2 \cdot \rightarrow \mathrm{C}=\mathrm{CO} \bullet+\mathrm{CC}=\mathrm{C}$ & $3.2 \mathrm{E}+11$ & 0.5 & 68.6 & $2.2 \mathrm{E}+09$ & $\mathrm{c}$ \\
\hline 49 & $\mathrm{C}=\mathrm{COCC} 2 \cdot \rightarrow \mathrm{CH}_{3}+\mathrm{C}=\mathrm{COC}=\mathrm{C}$ & $1.6 \mathrm{E}+12$ & 0.5 & 128.6 & $6.9 \mathrm{E}+06$ & $\mathrm{c}$ \\
\hline 50 & $\mathrm{C}=\mathrm{COCC} 2 \bullet \rightarrow \mathrm{a}-\mathrm{C} \cdot \operatorname{cy}(\mathrm{COC}(\mathrm{C}) \mathrm{C})$ & $1.0 \mathrm{E}+09$ & 0.6 & 59.0 & $5.2 \mathrm{E}+07$ & anti, c \\
\hline 51 & $\mathrm{C}=\mathrm{COCC} 2 \bullet \rightarrow \mathrm{s}-\mathrm{C} \cdot \operatorname{cy}(\mathrm{COC}(\mathrm{C}) \mathrm{C})$ & $1.1 \mathrm{E}+09$ & 0.6 & 55.6 & $7.0 \mathrm{E}+07$ & syn, c \\
\hline 52 & $\mathrm{Ccy}(\mathrm{COC} \cdot \mathrm{CC}) \rightarrow \mathrm{CC} \cdot \mathrm{CCCHO}$ & $3.3 \mathrm{E}+12$ & 0.3 & 94.4 & $3.2 \mathrm{E}+08$ & $\mathrm{c}$ \\
\hline 53 & $\mathrm{CC} \cdot \mathrm{CCCHO} \rightarrow \mathrm{C}=\mathrm{CO} \cdot+\mathrm{CC}=\mathrm{C}$ & $3.6 \mathrm{E}+09$ & 1.0 & 85.5 & $9.9 \mathrm{E}+07$ & $\mathrm{c}$ \\
\hline 54 & $\mathrm{CC} \cdot \mathrm{CCCHO} \rightarrow \mathrm{CCCCC} \bullet(=\mathrm{O})$ & $7.3 \mathrm{E}+04$ & 1.9 & 62.1 & $1.9 \mathrm{E}+07$ & $\mathrm{c}$ \\
\hline 55 & $\mathrm{CCCCC} \bullet(=\mathrm{O}) \rightarrow \mathrm{CCCC} \bullet+\mathrm{CO}$ & $1.0 \mathrm{E}+11$ & 0.0 & 40.2 & $8.0 \mathrm{E}+08$ & $\mathrm{c}$ \\
\hline \multirow[t]{2}{*}{56} & \multirow{2}{*}{\multicolumn{6}{|c|}{$\mathrm{Ccy}(\mathrm{COCC} \cdot \mathrm{C})$}} \\
\hline & & & & & & \\
\hline 57 & $\mathrm{Ccy}(\mathrm{COCC} \cdot \mathrm{C}) \rightarrow \mathrm{C}=\mathrm{CCOC} \cdot \mathrm{C}$ & $4.4 \mathrm{E}+12$ & 0.2 & 136.1 & $1.7 \mathrm{E}+06$ & $\mathrm{c}$ \\
\hline 58 & $\mathrm{C}=\mathrm{CCOC} \cdot \mathrm{C} \rightarrow \mathrm{CH}_{3} \mathrm{CHO}+\mathrm{C}=\mathrm{CC} \cdot$ & $4.4 \mathrm{E}+09$ & 1.1 & 58.1 & $7.4 \mathrm{E}+09$ & $\mathrm{c}$ \\
\hline 59 & $\mathrm{C}=\mathrm{CCOC} \cdot \mathrm{C} \rightarrow \mathrm{a}-\mathrm{C} \cdot \mathrm{cy}(\mathrm{CCOC}(\mathrm{C}))$ & $6.1 \mathrm{E}+07$ & 0.9 & 54.6 & $3.8 \mathrm{E}+07$ & anti, c \\
\hline 60 & $\mathrm{C}=\mathrm{CCOC} \cdot \mathrm{C} \rightarrow \mathrm{s}-\mathrm{C} \cdot \operatorname{cy}(\mathrm{CCOC}(\mathrm{C}))$ & $1.2 \mathrm{E}+08$ & 0.9 & 57.7 & $4.4 \mathrm{E}+07$ & syn, c \\
\hline 61 & $\mathrm{Ccy}(\mathrm{COCC} \cdot \mathrm{C}) \rightarrow \mathrm{C}=\mathrm{CCC}(\mathrm{C}) \mathrm{O} \bullet$ & $2.0 \mathrm{E}+12$ & 0.3 & 130.4 & $2.2 \mathrm{E}+06$ & $\mathrm{c}$ \\
\hline 62 & $\mathrm{C}=\mathrm{CCC}(\mathrm{C}) \mathrm{O} \bullet \rightarrow \mathrm{CH}_{3} \mathrm{CHO}+\mathrm{C}=\mathrm{CC} \bullet$ & $1.8 \mathrm{E}+12$ & 0.4 & 19.9 & $2.1 \mathrm{E}+12$ & $\mathrm{c}$ \\
\hline 63 & $\mathrm{C}=\mathrm{CCC}(\mathrm{C}) \mathrm{O} \bullet \mathrm{CH}_{3}+\mathrm{C}=\mathrm{CCCHO}$ & $4.7 \mathrm{E}+13$ & 0.2 & 60.1 & $1.2 \mathrm{E}+11$ & $\mathrm{c}$ \\
\hline 64 & $\mathrm{C}=\mathrm{CCC}(\mathrm{C}) \mathrm{O} \bullet \rightarrow \mathrm{C}=\mathrm{CC} \cdot \mathrm{C}(\mathrm{C}) \mathrm{OH}$ & $2.3 \mathrm{E}+08$ & 1.3 & 74.0 & $2.5 \mathrm{E}+08$ & anti, c \\
\hline 65 & $\mathrm{C}=\mathrm{CCC}(\mathrm{C}) \mathrm{O} \bullet \rightarrow \mathrm{a}-\mathrm{C} \bullet \mathrm{cy}(\mathrm{COC}(\mathrm{C}) \mathrm{C})$ & $4.7 \mathrm{E}+10$ & 0.4 & 49.7 & $1.8 \mathrm{E}+09$ & syn, c \\
\hline 66 & $\mathrm{C}=\mathrm{CCC}(\mathrm{C}) \mathrm{O} \bullet \rightarrow \mathrm{s}-\mathrm{C} \bullet \mathrm{cy}(\mathrm{COC}(\mathrm{C}) \mathrm{C})$ & $2.2 \mathrm{E}+10$ & 0.4 & 46.0 & $1.3 \mathrm{E}+09$ & $\mathrm{c}$ \\
\hline 67 & $\mathrm{Ccy}(\mathrm{COCC} \cdot \mathrm{C}) \rightarrow \mathrm{H}+\mathrm{Ccy}(\mathrm{COC}=\mathrm{CC})$ & $9.2 \mathrm{E}+09$ & 1.1 & 137.6 & $1.5 \mathrm{E}+06$ & $\mathrm{~b}$ \\
\hline \multirow[t]{2}{*}{68} & $\mathrm{Ccy}(\mathrm{COCC} \cdot \mathrm{C}) \rightarrow \mathrm{H}+\mathrm{Ccy}(\mathrm{COCC}=\mathrm{C})$ & $1.7 \mathrm{E}+10$ & 1.1 & 149.4 & $5.1 \mathrm{E}+05$ & $\mathrm{~b}$ \\
\hline & \multicolumn{6}{|l|}{$\operatorname{Ccy}(C O C C C \cdot)$} \\
\hline 69 & $\mathrm{Ccy}(\mathrm{COCCC} \bullet) \rightarrow \mathrm{C}=\mathrm{CC}(\mathrm{C}) \mathrm{OC} \bullet$ & $1.4 \mathrm{E}+12$ & 0.5 & 136.6 & $2.8 \mathrm{E}+06$ & $\mathrm{c}$ \\
\hline 70 & $\mathrm{C}=\mathrm{CC}(\mathrm{C}) \mathrm{OC} \bullet \rightarrow \mathrm{CH}_{2} \mathrm{O}+\mathrm{c}-\mathrm{CC}=\mathrm{CC} \bullet$ & $8.0 \mathrm{E}+11$ & 0.5 & 67.5 & $6.9 \mathrm{E}+09$ & $\mathrm{c}$ \\
\hline 71 & $\mathrm{C}=\mathrm{CC}(\mathrm{C}) \mathrm{OC} \bullet \rightarrow \mathrm{CH}_{2} \mathrm{O}+\mathrm{t}-\mathrm{CC}=\mathrm{CC} \bullet$ & $1.4 \mathrm{E}+11$ & 0.8 & 63.3 & $1.3 \mathrm{E}+10$ & $\mathrm{c}$ \\
\hline 72 & $\mathrm{C}=\mathrm{CC}(\mathrm{C}) \mathrm{OC} \bullet \rightarrow \mathrm{a}-\mathrm{C} \cdot \mathrm{cy}(\mathrm{CCOC}(\mathrm{C}))$ & $2.9 \mathrm{E}+09$ & 0.5 & 60.1 & $8.2 \mathrm{E}+07$ & anti, c \\
\hline 73 & $\mathrm{C}=\mathrm{CC}(\mathrm{C}) \mathrm{OC} \bullet \rightarrow \mathrm{s}-\mathrm{C} \bullet \operatorname{cy}(\mathrm{CCOC}(\mathrm{C}))$ & $1.2 \mathrm{E}+09$ & 0.6 & 66.9 & $2.7 \mathrm{E}+07$ & syn, c \\
\hline 74 & $\mathrm{Ccy}(\mathrm{COCCC} \bullet) \rightarrow \mathrm{t}-\mathrm{CC}=\mathrm{CCCO} \bullet$ & $2.8 \mathrm{E}+13$ & -0.1 & 127.0 & $4.8 \mathrm{E}+06$ & trans, c \\
\hline 75 & $\mathrm{Ccy}(\mathrm{COCCC} \bullet) \rightarrow \mathrm{c}-\mathrm{CC}=\mathrm{CCCO} \bullet$ & $6.3 \mathrm{E}+12$ & 0.1 & 136.7 & $7.8 \mathrm{E}+05$ & cis, c \\
\hline 76 & $\mathrm{t}-\mathrm{CC}=\mathrm{CCCO} \bullet \rightarrow \mathrm{t}-\mathrm{C}=\mathrm{CC} \cdot \mathrm{CCOH}$ & $3.1 \mathrm{E}+04$ & 1.9 & 132.5 & $2.5 \mathrm{E}+03$ & trans, $\mathrm{c}$ \\
\hline 77 & $\mathrm{t}-\mathrm{CC}=\mathrm{CCCO} \bullet \rightarrow \mathrm{t}-\mathrm{CC}=\mathrm{CC} \cdot \mathrm{COH}$ & $8.1 \mathrm{E}+07$ & 1.4 & 80.8 & $9.5 \mathrm{E}+07$ & trans, $\mathrm{c}$ \\
\hline 78 & $\mathrm{c}-\mathrm{CC}=\mathrm{CCCO} \bullet \rightarrow \mathrm{c}-\mathrm{C}=\mathrm{CC} \cdot \mathrm{CCOH}$ & $2.1 \mathrm{E}+06$ & 1.4 & 18.8 & $3.5 \mathrm{E}+09$ & cis, c \\
\hline 79 & $\mathrm{c}-\mathrm{CC}=\mathrm{CCCO} \bullet \rightarrow \mathrm{c}-\mathrm{CC}=\mathrm{CC} \cdot \mathrm{COH}$ & $3.1 \mathrm{E}+07$ & 1.5 & 79.5 & $7.6 \mathrm{E}+07$ & cis, c \\
\hline 80 & $\mathrm{t}-\mathrm{CC}=\mathrm{CCCO} \bullet \rightarrow \mathrm{CH}_{2} \mathrm{O}+\mathrm{t}-\mathrm{CC}=\mathrm{CC} \bullet$ & $5.7 \mathrm{E}+11$ & 0.5 & 25.7 & $6.8 \mathrm{E}+11$ & trans, $\mathrm{c}$ \\
\hline 81 & $\mathrm{c}-\mathrm{CC}=\mathrm{CCCO} \bullet \rightarrow \mathrm{CH}_{2} \mathrm{O}+\mathrm{c}-\mathrm{CC}=\mathrm{CC} \bullet$ & $1.1 \mathrm{E}+12$ & 0.4 & 24.7 & $9.2 \mathrm{E}+11$ & cis, c \\
\hline 82 & $\mathrm{Ccy}(\mathrm{COCCC} \bullet) \rightarrow \mathrm{H}+\mathrm{Ccy}(\mathrm{C}=\mathrm{CCCO})$ & $9.2 \mathrm{E}+09$ & 1.1 & 137.6 & $1.5 \mathrm{E}+06$ & $\mathrm{~b}$ \\
\hline 83 & $\mathrm{Ccy}(\mathrm{COCCC} \bullet) \rightarrow \mathrm{H}+\mathrm{Ccy}(\mathrm{COCC}=\mathrm{C})$ & $1.7 \mathrm{E}+10$ & 1.1 & 149.4 & $5.1 \mathrm{E}+05$ & $\mathrm{~b}$ \\
\hline \multirow[t]{2}{*}{84} & $\mathrm{Ccy}(\mathrm{COCCC} \cdot) \rightarrow \mathrm{CH}_{3}+\operatorname{cy}(\mathrm{OC}=\mathrm{CCC})$ & $1.5 \mathrm{E}+13$ & 0.3 & 129.2 & $2.7 \mathrm{E}+07$ & $\mathrm{c}$ \\
\hline & \multicolumn{6}{|l|}{$\operatorname{Ccy}(C \cdot O C C C)$} \\
\hline 85 & $\mathrm{Ccy}(\mathrm{C} \cdot \mathrm{OCCC}) \rightarrow \mathrm{C} \cdot \mathrm{CCC}(=\mathrm{O}) \mathrm{C}$ & $1.4 \mathrm{E}+12$ & 0.5 & 90.7 & $9.2 \mathrm{E}+08$ & $\mathrm{c}$ \\
\hline 86 & $\mathrm{C} \cdot \mathrm{CCC}(=\mathrm{O}) \mathrm{C} \rightarrow \mathrm{C} 2 \cdot \mathrm{C}=\mathrm{O}+\mathrm{C}_{2} \mathrm{H}_{4}$ & $1.2 \mathrm{E}+11$ & 0.7 & 92.4 & $2.2 \mathrm{E}+08$ & $\mathrm{c}$ \\
\hline 87 & $\mathrm{C} \cdot \mathrm{CCC}(=\mathrm{O}) \mathrm{C} \rightarrow \mathrm{CCCC}(=\mathrm{O}) \mathrm{C} \bullet$ & $2.5 \mathrm{E}+04$ & 1.9 & 56.1 & $1.4 \mathrm{E}+07$ & $\mathrm{c}$ \\
\hline 88 & $\mathrm{Ccy}(\mathrm{C} \cdot \mathrm{OCCC}) \rightarrow \mathrm{C}=\mathrm{C}(\mathrm{C}) \mathrm{OCC} \bullet$ & $7.2 \mathrm{E}+11$ & 0.7 & 136.9 & $4.6 \mathrm{E}+06$ & $\mathrm{c}$ \\
\hline 89 & $\mathrm{C}=\mathrm{C}(\mathrm{C}) \mathrm{OCC} \bullet \rightarrow \mathrm{C} 2 \cdot \mathrm{C}=\mathrm{O}+\mathrm{C}_{2} \mathrm{H}_{4}$ & $2.8 \mathrm{E}+13$ & 0.1 & 75.9 & $4.8 \mathrm{E}+09$ & $\mathrm{c}$ \\
\hline \multirow[t]{2}{*}{90} & $\mathrm{Ccy}(\mathrm{C} \cdot \mathrm{OCCC}) \rightarrow \mathrm{H}+\mathrm{Ccy}(\mathrm{C}=\mathrm{CCCO})$ & $2.8 \mathrm{E}+04$ & 2.7 & 191.1 & $3.6 \mathrm{E}+02$ & $\mathrm{~b}$ \\
\hline & \multicolumn{6}{|l|}{$C \cdot c y(C O C C C)$} \\
\hline 91 & $\mathrm{C} \cdot \mathrm{cy}(\mathrm{COCCC}) \rightarrow \mathrm{C}=\mathrm{CCCCO} \bullet$ & $4.8 \mathrm{E}+10$ & 0.6 & 75.8 & $2.4 \mathrm{E}+08$ & $\mathrm{c}$ \\
\hline 92 & $\mathrm{C}=\mathrm{CCCCO} \bullet \rightarrow \mathrm{CH}_{2} \mathrm{O}+\mathrm{C}=\mathrm{CCC} \bullet$ & $1.3 \mathrm{E}+14$ & 0.0 & 57.4 & $1.7 \mathrm{E}+11$ & $\mathrm{c}$ \\
\hline 93 & $\mathrm{C}=\mathrm{CCCCO} \bullet \rightarrow \operatorname{cy}(\mathrm{OCC} \bullet \mathrm{CCC})$ & $1.1 \mathrm{E}+09$ & 0.3 & 12.3 & $2.2 \mathrm{E}+09$ & $\mathrm{c}$ \\
\hline 94 & $\mathrm{C}=\mathrm{CCCCO} \bullet \rightarrow \mathrm{C}=\mathrm{CC} \cdot \mathrm{CCOH}$ & $3.6 \mathrm{E}+07$ & 1.2 & 51.1 & $3.0 \mathrm{E}+08$ & $\mathrm{c}$ \\
\hline
\end{tabular}




\begin{tabular}{llccccc}
95 & $\mathrm{C} \cdot \mathrm{cy}(\mathrm{COCCC}) \rightarrow \mathrm{C} \cdot \mathrm{CCOC}=\mathrm{C}$ & $1.1 \mathrm{E}+10$ & 0.8 & 90.0 & $7.2 \mathrm{E}+07$ & $\mathrm{c}$ \\
96 & $\mathrm{C} \cdot \mathrm{CCOC}=\mathrm{C} \rightarrow \mathrm{C}=\mathrm{COC} \cdot+\mathrm{C}_{2} \mathrm{H}_{4}$ & $1.2 \mathrm{E}+12$ & 0.4 & 116.4 & $1.9 \mathrm{E}+07$ & $\mathrm{c}$ \\
97 & $\mathrm{C} \cdot \mathrm{CCOC}=\mathrm{C} \rightarrow \mathrm{cy}(\mathrm{OC} \cdot \mathrm{CCCC})$ & $2.0 \mathrm{E}+08$ & 0.6 & 48.4 & $3.0 \mathrm{E}+07$ & $\mathrm{c}$ \\
& Substitution & & & & & \\
98 & $\mathrm{Ccy}(\mathrm{COCCC})+\mathrm{H} \rightarrow \mathrm{CC} \cdot \mathrm{CCCOH}$ & $3.9 \mathrm{E}+00$ & 2.0 & 99.6 & $2.0 \mathrm{E}+01$ & $\mathrm{c}$ \\
\hline
\end{tabular}

a estimated

$\mathrm{b}$ reaction rate coefficient taken from its THF analogue [10]

c CBS-QB3 calculated value, see Section 2.4

d estimated from Evans-Polanyi relationship [34]

e taken from [15] 


\section{Figure captions}

Fig. 1 Structure of MTHF with atom labels (red italic) and bond bond energy in $\mathrm{kJ} \mathrm{mol}^{-1}[14]$ (black bold)

Fig. 2 MTHF flame temperature profiles as a function of height above burner $h$ at $\varphi=1.0$ : measured profile without the sampling probe, $\boldsymbol{\Delta}-$ measured profile and with the sampling probe, temperature profile used for simulation

Fig. 3 C-O scission in THF and MTHF forming carbene intermediates and subsequent decomposition.

Fig. 4 Unimolecular consumption reactions of tetrahydro-2-methyl-4-furanyl and derived radicals

Fig. 5 Mole fractions as a function of temperature for MTHF pyrolysis in a tubular reactor, $\mathrm{P}=0.17 \mathrm{MPa}, \mathrm{F}_{\mathrm{MTHF}}=1.6710^{-4} \mathrm{~mol} \mathrm{~s}^{-1}, \mathrm{~F}_{\mathrm{N} 2}=1.6710^{-3} \mathrm{~mol}^{-1}$; symbols, experimental mole fraction profile of molecule represented in graph; lines, mole fraction profiles calculated with CHEMKIN-PRO using the plug flow reactor model and the developed kinetic model, discussed in section 3

Fig. 6 Main reaction paths in MTHF pyrolysis, identified using CHEMKIN-PRO. Operating conditions correspond to $\mathrm{P}=0.17 \mathrm{MPa}, \mathrm{F}_{\mathrm{MTHF}}=1.6710^{-4} \mathrm{~mol} \mathrm{~s}^{-1}, \mathrm{~F}_{\mathrm{N} 2}=1.6710^{-3} \mathrm{~mol} \mathrm{~s}^{-1}$, conversion $_{\mathrm{MTHF}}=10 \%, \mathrm{~T}=950 \mathrm{~K}(\mathrm{z}=1.39 \mathrm{~m}), \mathrm{T}=1000 \mathrm{~K}(\mathrm{z}=0.24 \mathrm{~m}), \mathrm{T}=1050 \mathrm{~K}(\mathrm{z}=0.05 \mathrm{~m})$. A percentage next to a reaction pathway represents the rate of that reaction relative to the total MTHF consumption rate, blue italic, black normal and red underlined values correspond to $950 \mathrm{~K}, 1000 \mathrm{~K}$ and 1050 respectively.

Fig. 7 Mole fraction profiles as a function of height above burner for $\varphi=0.7$ (left), $\varphi=1.0$ (middle) and $\varphi=1.3$ (right); symbols, experimental mole fraction profile of molecule represented in graph; lines, mole fraction profiles calculated with CHEMKIN using the premixed laminar flame model and the developed kinetic model, discussed in section 3

Fig. 8 Mole fraction profiles as a function of height above burner for $\varphi=0.7$ (left), $\varphi=1.0$ (middle) and $\varphi=1.3$ (right); symbols, experimental mole fraction profile of molecule represented in graph; lines, mole fraction profiles calculated with CHEMKIN using the premixed laminar flame model and the developed kinetic model, discussed in section 3

Fig. 9 Mole fraction profiles as a function of height above burner for $\varphi=0.7$ (left), $\varphi=1.0$ (middle) and $\varphi=1.3$ (right); symbols, experimental mole fraction profile of molecule represented in graph; lines, mole fraction profiles calculated with CHEMKIN using the premixed laminar flame model and the developed kinetic model, discussed in section 3 
Fig. 10 Mole fraction profiles as a function of height above burner for $\varphi=0.7$ (left), $\varphi=1.0$ (middle) and $\varphi=1.3$ (right); symbols, experimental mole fraction profile of molecule represented in graph; lines, mole fraction profiles calculated with CHEMKIN using the premixed laminar flame model and the developed kinetic model, discussed in section 3

Fig. 11 Mole fraction profiles as a function of height above burner for $\varphi=1.7$ using synchrotronbased tunable VUV PI-MBMS obtained by Moshammer et al.[17]; symbols, experimental mole fraction profile of molecule represented in graph; lines, mole fraction profiles calculated with CHEMKIN using the premixed laminar flame model: — - the developed kinetic model, discussed in section 3, .... the kinetic model developed by Moshammer et al. [17]

Fig. 12 Main reaction paths in MTHF premixed low-pressure laming flames, identified using CHEMKIN-PRO. Operating conditions correspond to $\mathrm{P}=6.66 \mathrm{kPa}, \varphi=1.0$. A percentage next to a reaction pathway represents the rate of that reaction relative to the total MTHF consumption rate.

Fig. 13 Laminar burning velocities for MTHF-air flames at $0.101 \mathrm{MPa}$ : - - unburned gas temperature of $298 \mathrm{~K}$, - unburned gas temperature of $358 \mathrm{~K}, \bullet$ - unburned gas temperature of 398K; lines, profiles calculated with CHEMKIN using the premixed laminar flame model and the developed kinetic model, discussed in section 3

Fig. 14 Sensitivity coefficients for MTHF laminar burning velocities. Operating conditions correspond to $\varphi=1.1, \mathrm{P}=0.101 \mathrm{MPa}$ and unburned gas temperature of $298 \mathrm{~K}$. Coefficients for the seven most sensitive reactions and coefficients for six other reactions, related to consumption of MTHF and related decomposition products, are displayed.

Fig. 15 Experimental laminar burning velocity at $0.101 \mathrm{MPa}$, unburned gas temperature of 298K, $\varphi=1.1$ for tetrahydrofuran [10], 2-methyl-tetrahydrofuran (this work), tetrahydropyran [35], 2methyl-furan [62] and 2,5-dimethylfuran [63] 


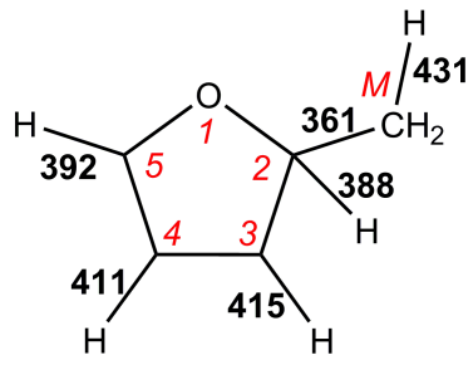

Fig. 1. Structure of MTHF with atom labels (red italic) and bond bond energy in $\mathrm{kJ} \mathrm{mol}^{-1}$ [14] (black bold) 


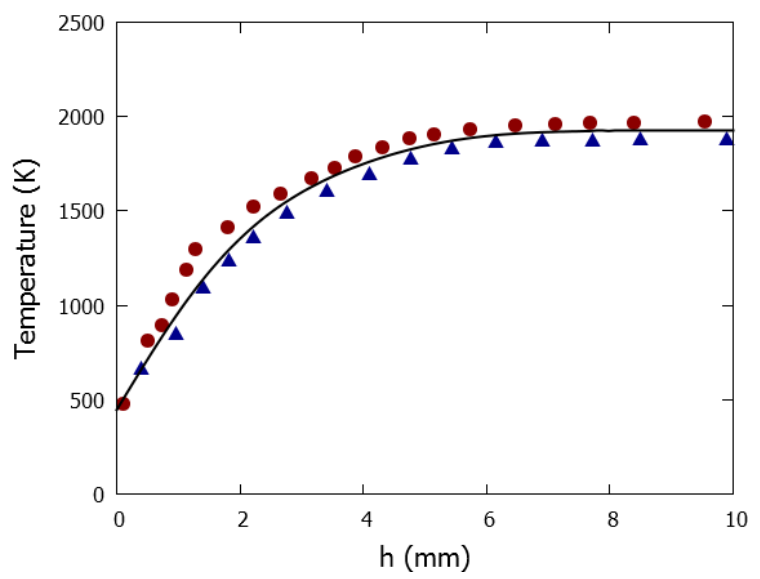

Fig. 2 MTHF flame temperature profiles as a function of height above burner $h$ at $\varphi=1.0$ : $\bullet$ measured profile without the sampling probe, $\Delta$ - measured profile and with the sampling probe, temperature profile used for simulation 


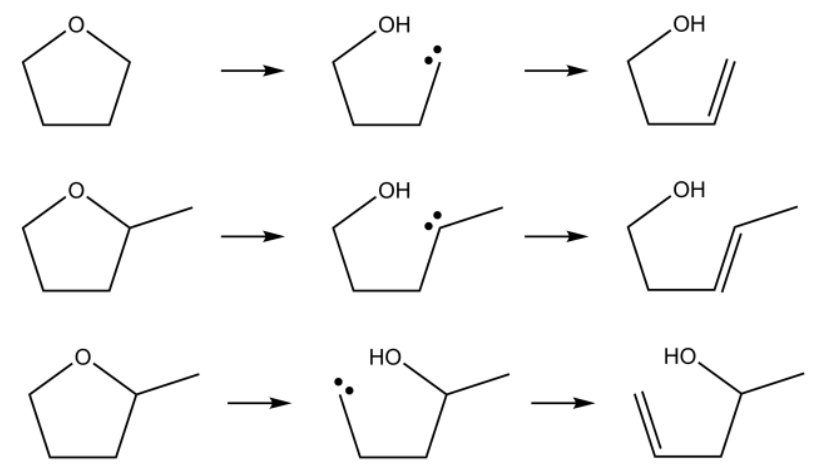

Fig. 3 C-O scission in THF and MTHF forming carbene intermediates and subsequent decomposition. 


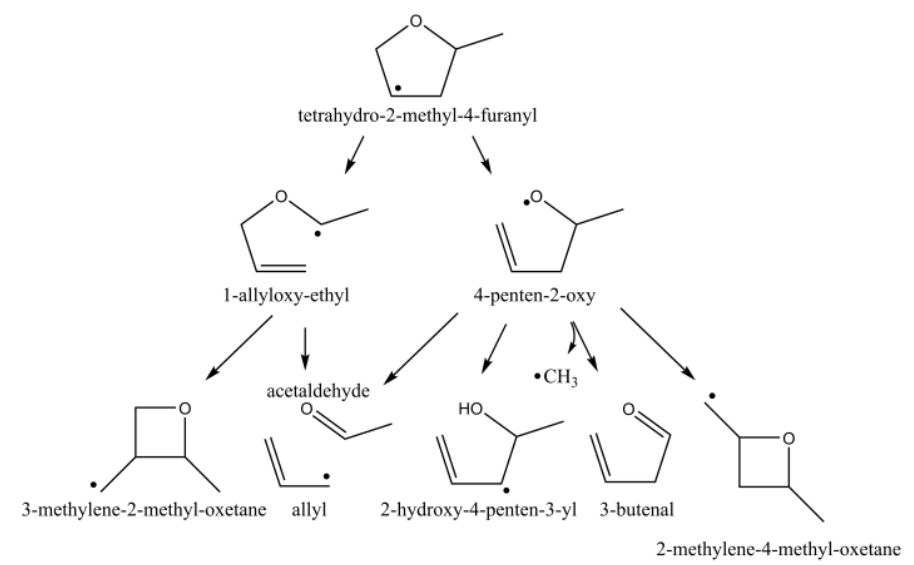

Fig. 4 Unimolecular consumption reactions of tetrahydro-2-methyl-4-furanyl and derived radicals 

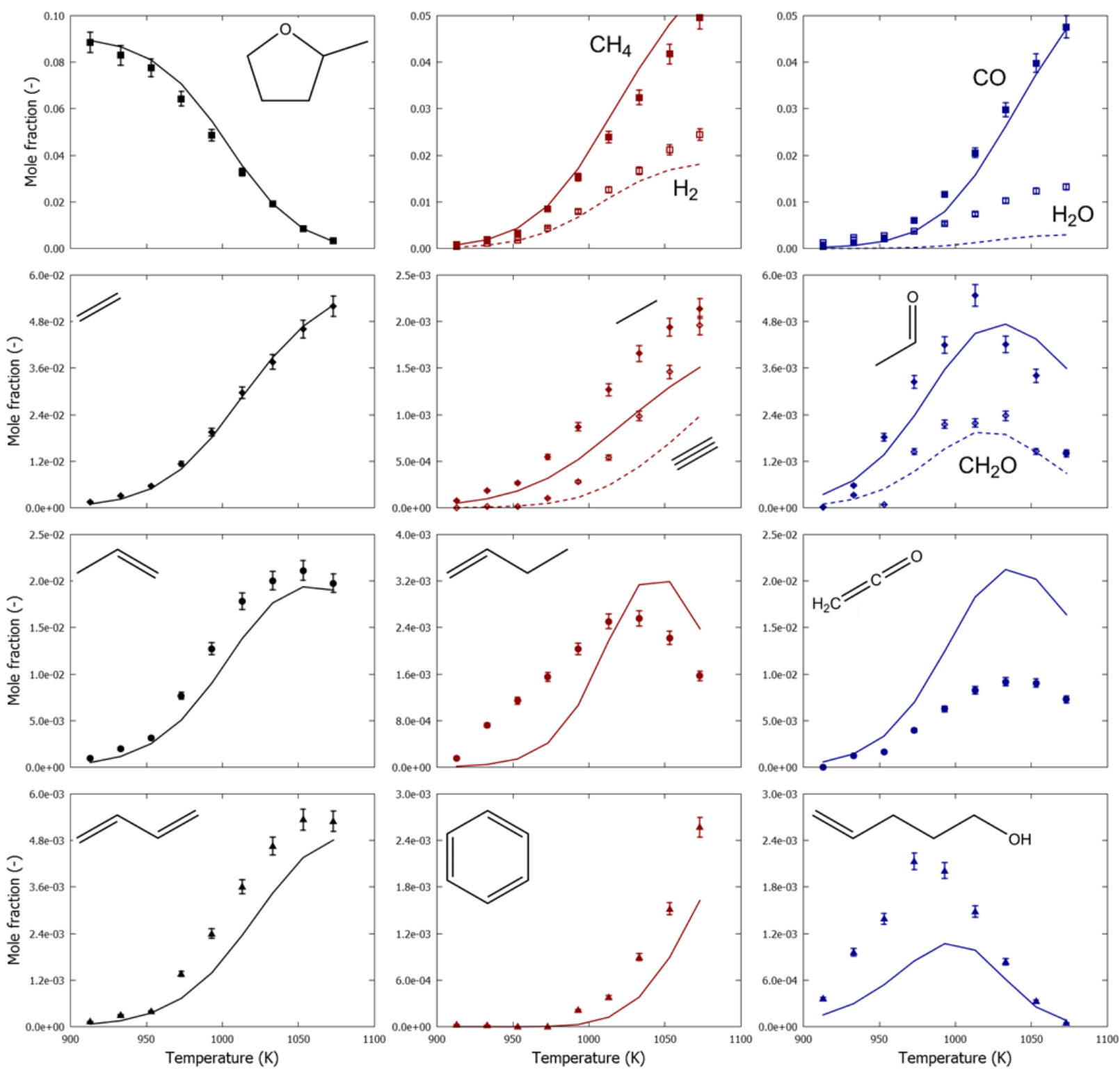

Fig. 5 Mole fractions as a function of temperature for MTHF pyrolysis in a tubular reactor, $P=0.17$ $\mathrm{MPa}, \mathrm{F}_{\mathrm{MTHF}}=1.6710^{-4} \mathrm{~mol} \mathrm{~s}^{-1}, \mathrm{~F}_{\mathrm{N} 2}=1.67 \mathbf{1 0}^{-3} \mathrm{~mol}^{-1}$; symbols, experimental mole fraction profile of molecule represented in graph; lines, mole fraction profiles calculated with CHEMKIN-PRO using the plug flow reactor model and the developed kinetic model, discussed in section 3 


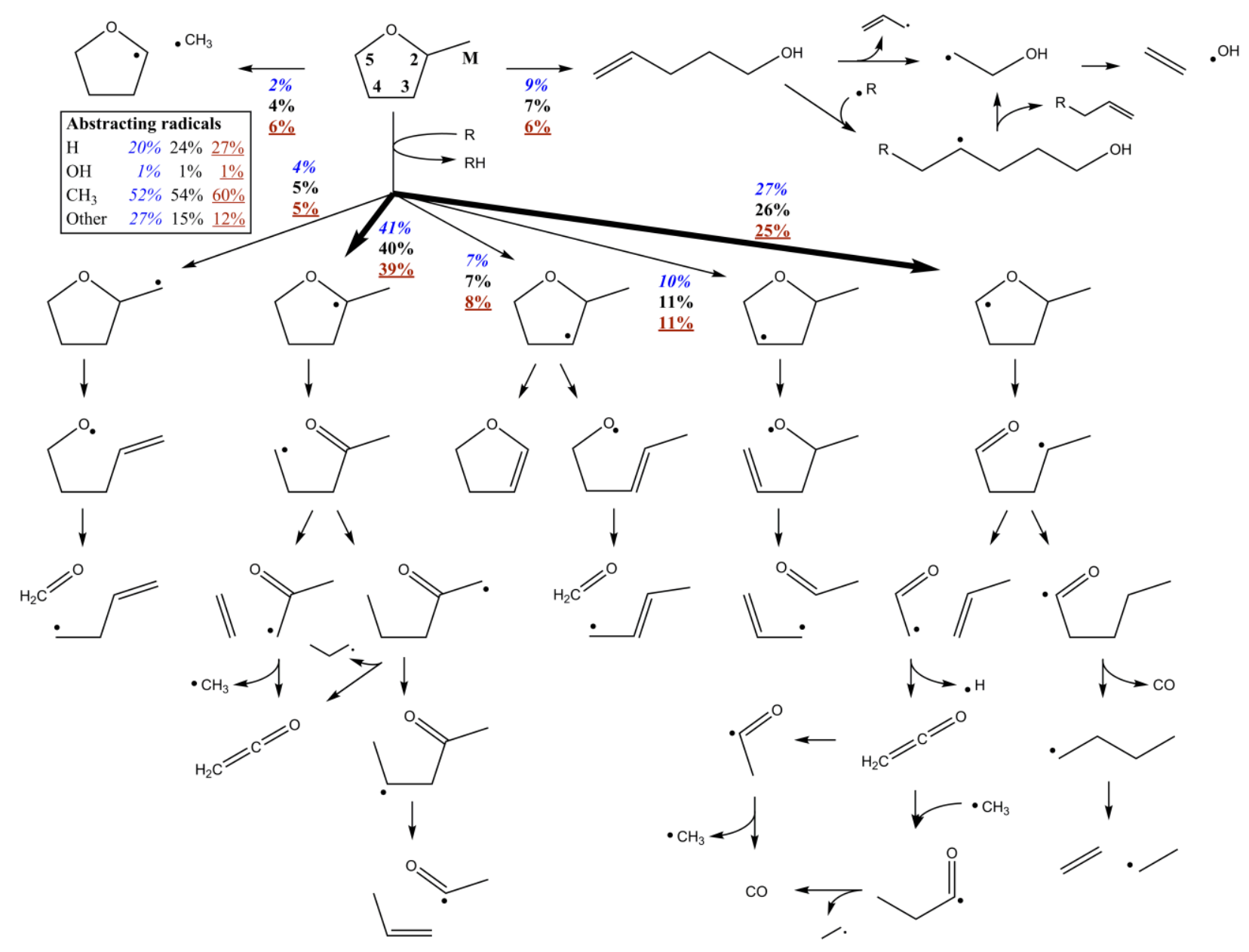

Fig. 6 Main reaction paths in MTHF pyrolysis, identified using CHEMKIN-PRO. Operating conditions correspond to $P=0.17 \mathrm{MPa}, F_{\mathrm{MTHF}}=1.6710^{-4} \mathrm{~mol} \mathrm{~s}^{-1}, F_{\mathrm{N} 2}=1.6710^{-3} \mathrm{~mol} \mathrm{~s}^{-1}$, conversion $_{\mathrm{MTHF}}=10 \%, \mathrm{~T}=950 \mathrm{~K}(\mathrm{z}=1.39 \mathrm{~m}), \mathrm{T}=1000 \mathrm{~K}(\mathrm{z}=0.24 \mathrm{~m}), \mathrm{T}=1050 \mathrm{~K}(\mathrm{z}=0.05 \mathrm{~m}) . A$ percentage next to a reaction pathway represents the rate of that reaction relative to the total MTHF consumption rate, blue italic, black normal and red underlined values correspond to $950 \mathrm{~K}$, $1000 \mathrm{~K}$ and 1050 respectively. 

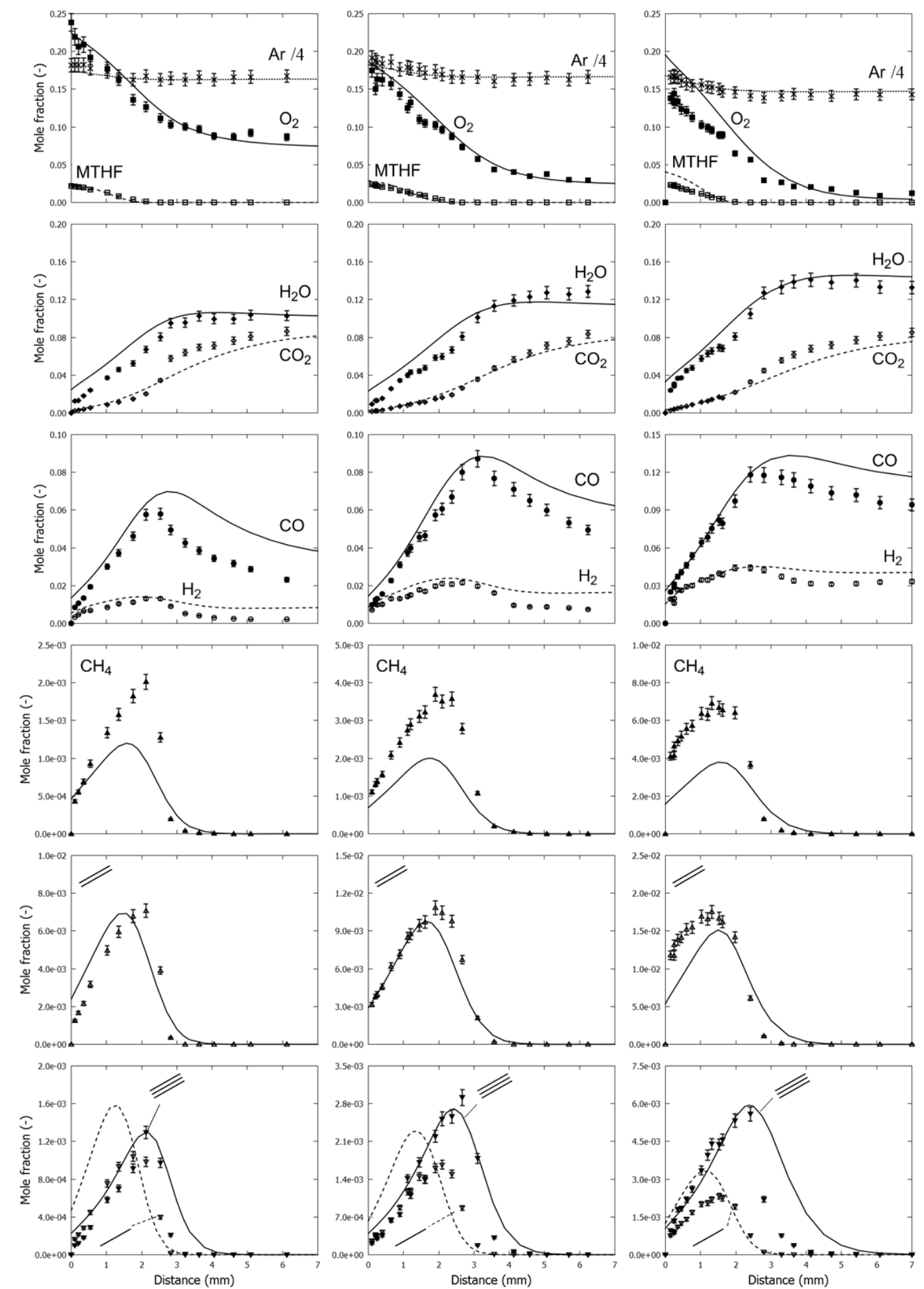

Fig. 7 Mole fraction profiles as a function of height above burner for $\varphi=0.7$ (left), $\varphi=1.0$ (middle) and $\varphi=1.3$ (right); symbols, experimental mole fraction profile of molecule represented in graph; lines, mole fraction profiles calculated with CHEMKIN using the premixed laminar flame model and the developed kinetic model, discussed in section 3 

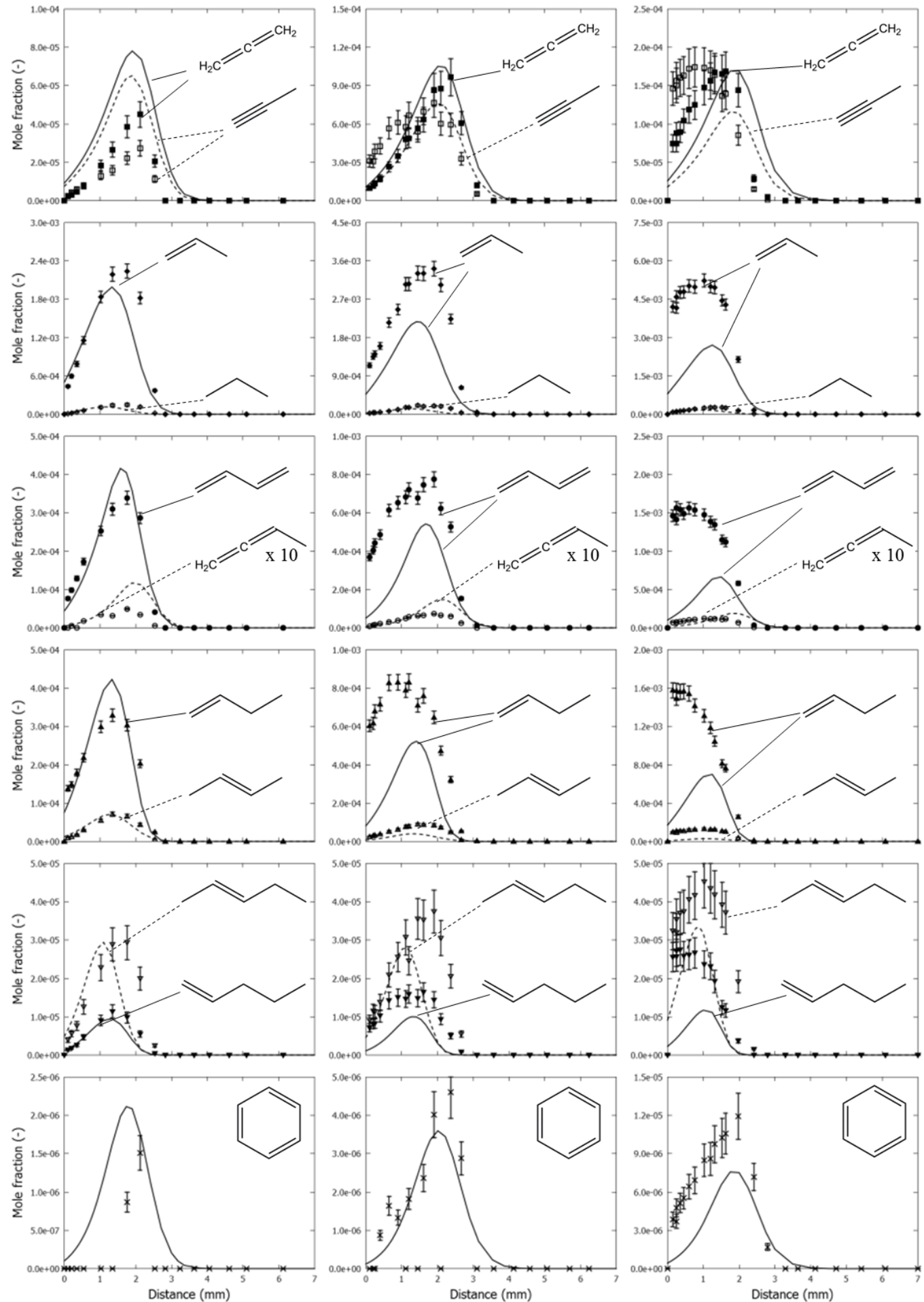

Fig. 8 Mole fraction profiles as a function of height above burner for $\varphi=0.7$ (left), $\varphi=1.0$ (middle) and $\varphi=1.3$ (right); symbols, experimental mole fraction profile of molecule represented in graph; lines, mole fraction profiles calculated with CHEMKIN using the premixed laminar flame model and the developed kinetic model, discussed in section 3 

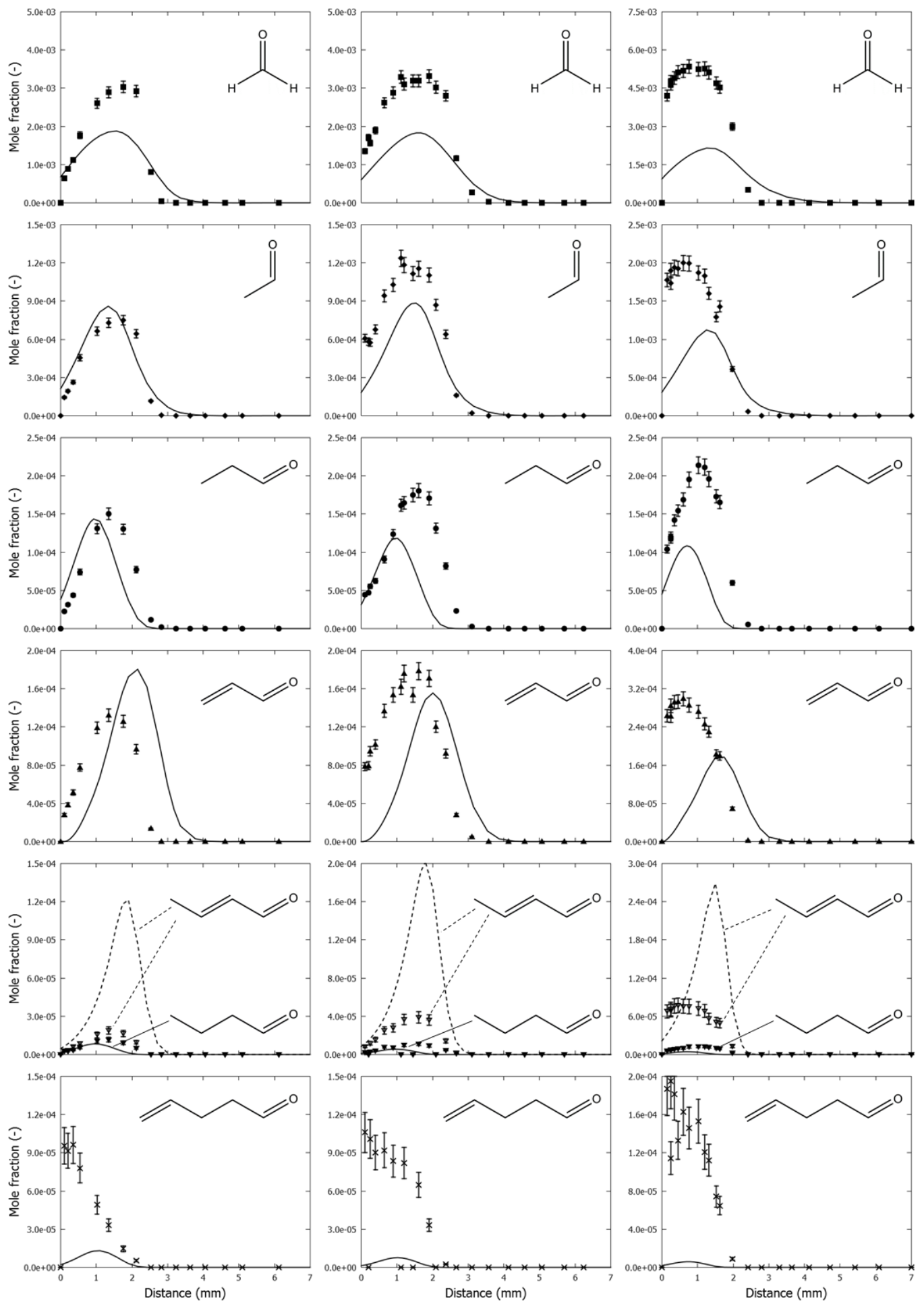

Fig. 9 Mole fraction profiles as a function of height above burner for $\varphi=0.7$ (left), $\varphi=1.0$ (middle) and $\varphi=1.3$ (right); symbols, experimental mole fraction profile of molecule represented in graph; lines, mole fraction profiles calculated with CHEMKIN using the premixed laminar flame model and the developed kinetic model, discussed in section 3 

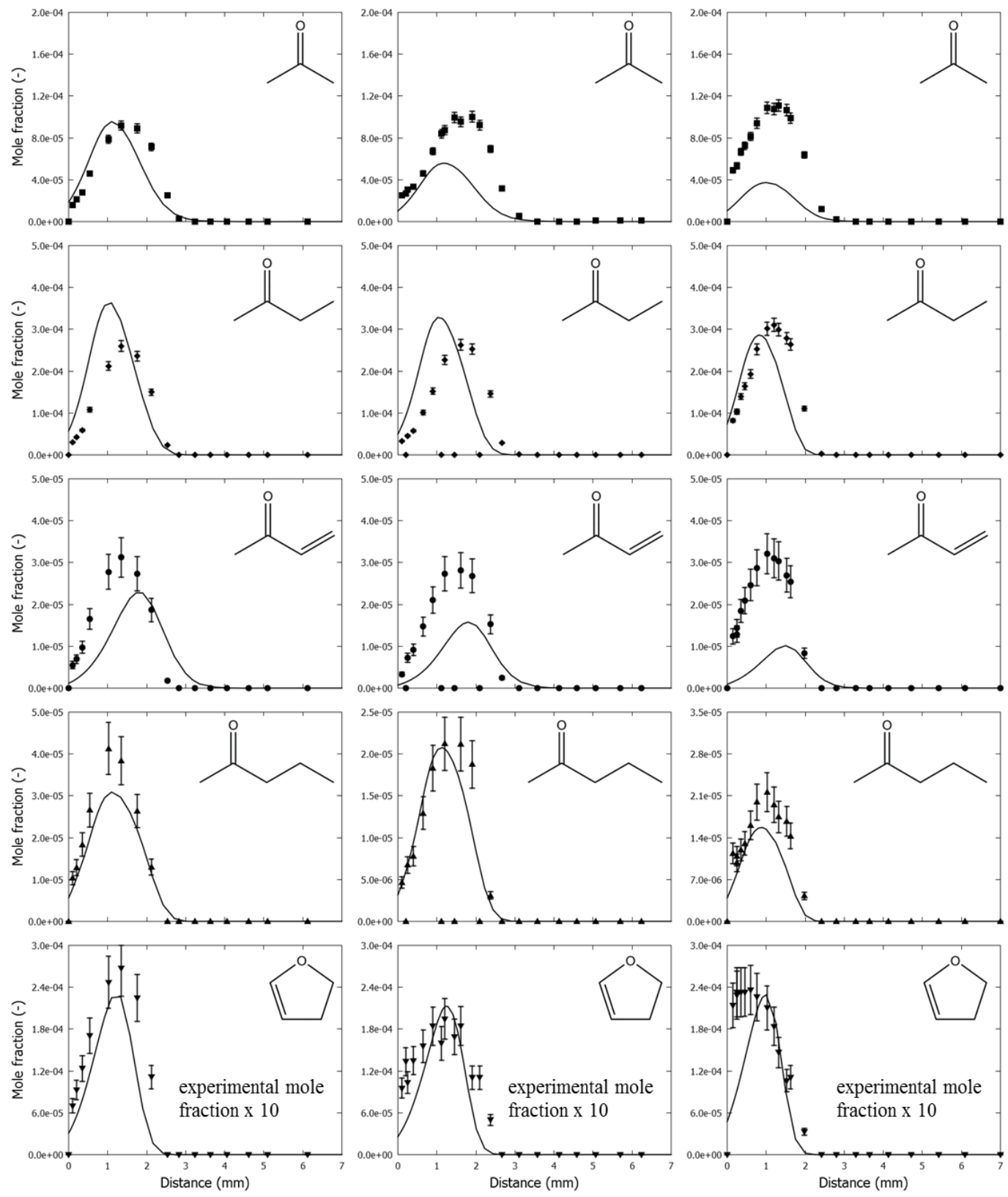

Fig. 10 Mole fraction profiles as a function of height above burner for $\varphi=0.7$ (left), $\varphi=1.0$ (middle) and $\varphi=1.3$ (right); symbols, experimental mole fraction profile of molecule represented in graph; lines, mole fraction profiles calculated with CHEMKIN using the premixed laminar flame model and the developed kinetic model, discussed in section 3 

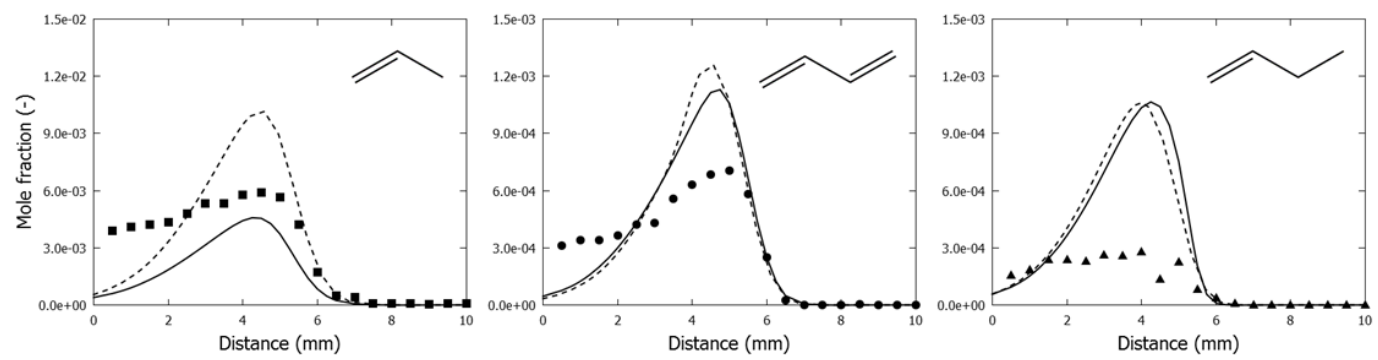

Fig. 11 Mole fraction profiles as a function of height above burner for $\varphi=1.7$ using synchrotronbased tunable VUV PI-MBMS obtained by Moshammer et al.[17]; symbols, experimental mole fraction profile of molecule represented in graph; lines, mole fraction profiles calculated with CHEMKIN using the premixed laminar flame model: - - the developed kinetic model, discussed in section 3, ..... the kinetic model developed by Moshammer et al. [17] 


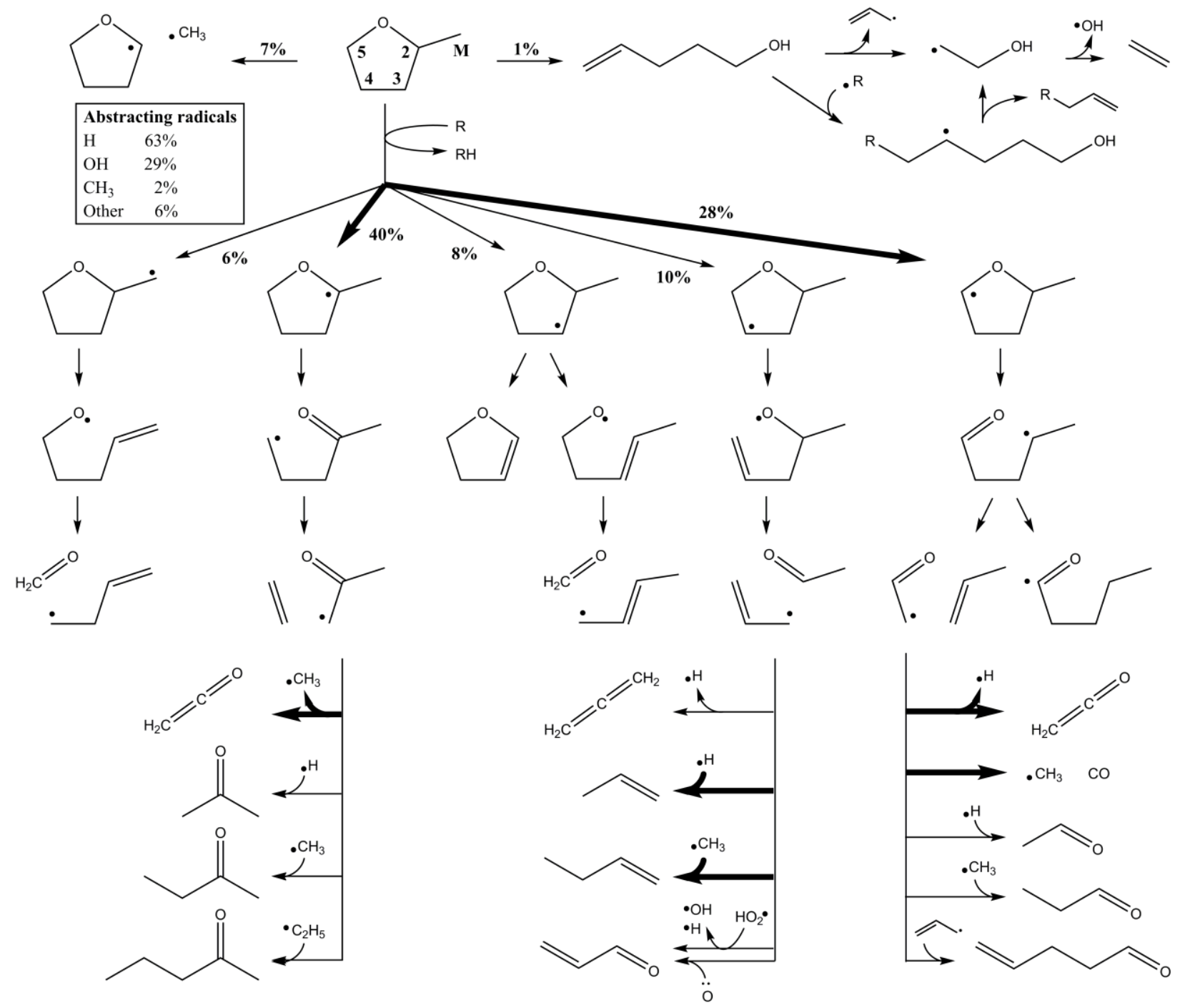

Fig. 12 Main reaction paths in MTHF premixed low-pressure laming flames, identified using CHEMKIN-PRO. Operating conditions correspond to $P=6.66 \mathrm{kPa}, \varphi=1.0$, conversion ${ }_{\mathrm{MTHF}}=90 \%$. A percentage next to a reaction pathway represents the rate of that reaction relative to the total MTHF consumption rate. 


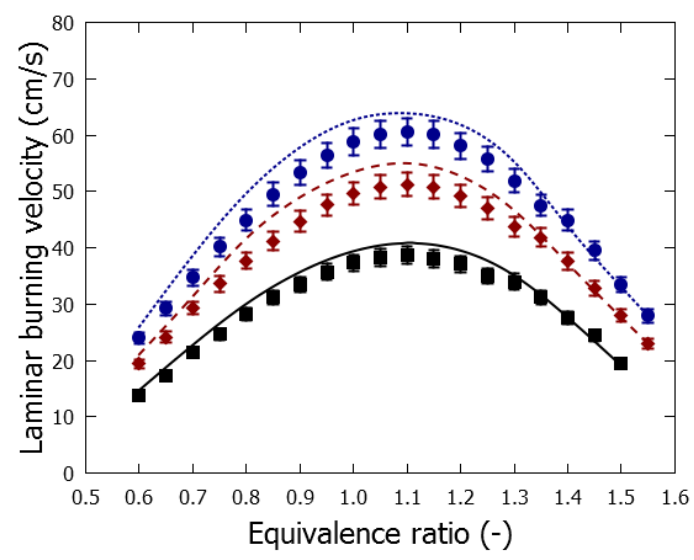

Fig. 13 Laminar burning velocities for MTHF-air flames at 0.101 MPa: — - unburned gas temperature of $298 \mathrm{~K}$, $\bullet$ - unburned gas temperature of $358 \mathrm{~K}, \bullet-$ unburned gas temperature of 398K; lines, profiles calculated with CHEMKIN using the premixed laminar flame model and the developed kinetic model, discussed in section 3. Error bars correspond to 5\%, also see section 2.3. 


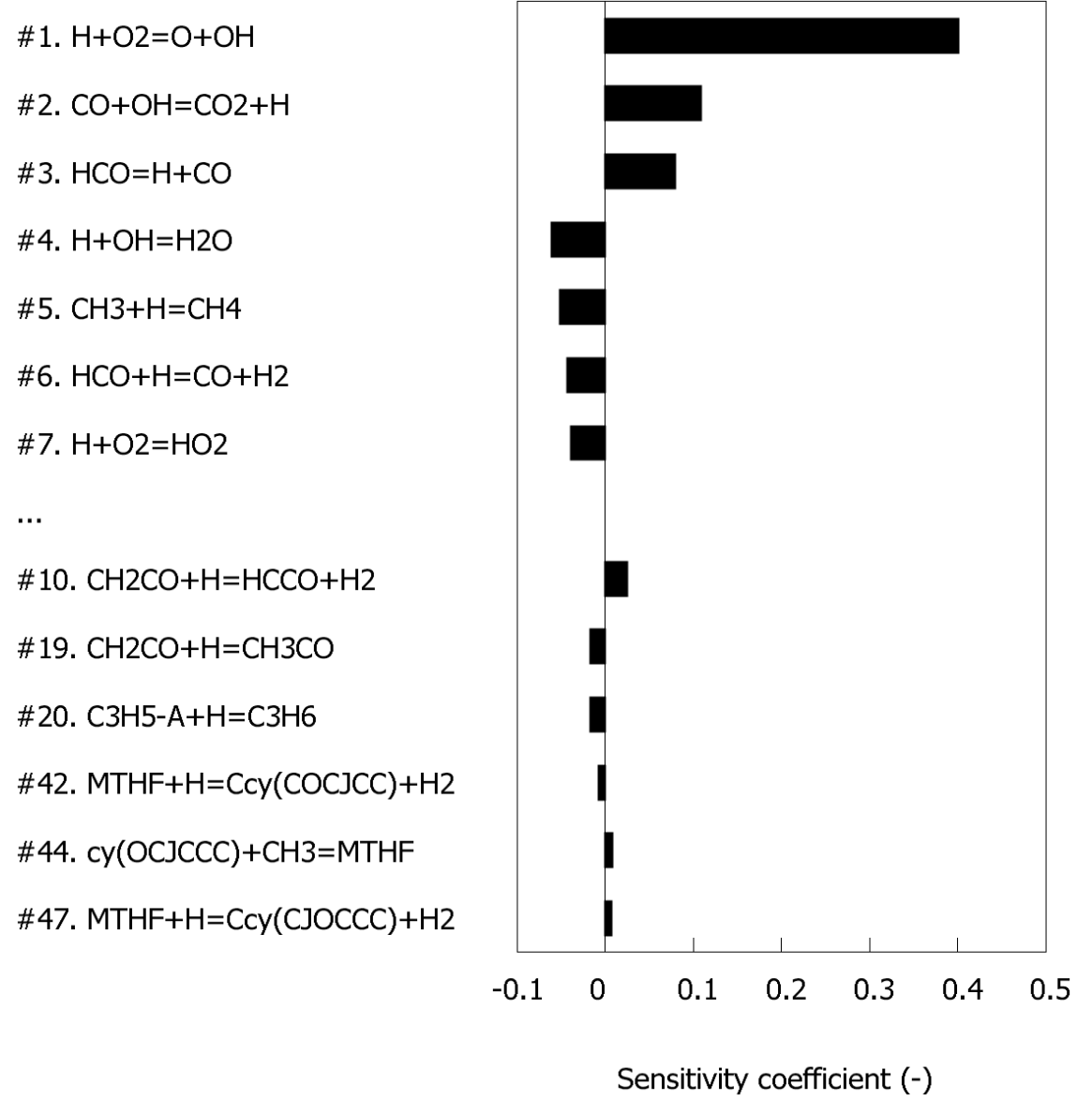

Fig. 14 Sensitivity coefficients for MTHF laminar burning velocities. Operating conditions correspond to $\varphi=1.1, P=0.101 \mathrm{MPa}$ and unburned gas temperature of 298K. Coefficients for the seven most sensitive reactions and coefficients for six other reactions, related to consumption of MTHF and related decomposition products, are displayed. 